$$
\begin{gathered}
\text { 방제학 공통교재에 수재할 蕉香正氣散의 配伍 분석 } \\
\text { 신 순 식 }
\end{gathered}
$$

\title{
Analysis of Agastache Powder to Rectify the Ki Combination for the Formula Science Common Textbook
}

\author{
Soon Shik Shin* \\ Department of Formula Science, College of Korean Medicine \& Research \\ Center of Korean Medicine for Diabetes and Obesity, Dong-Eui University
}

\begin{abstract}
Objectives : Proposed a formula analysis standard about the individual formula which is to be put in the specific discussions in order to increase the effect of formula education at the college of Korean medicine.

Methods : Examined the ingredient combination analysis written in Agastache Powder to Rectify the Ki which was put in the 27 kinds of formula science book published in both Korea and China.

Results : Must analyze the formula according to the existing formula. The combination of the ingredients should be analyzed into herb pairs such as seven different combinations. The effect and disease for which medicine is efficacious, should be analyzed and tabulated by Agastache Powder to Rectify the Ki. The formula should be anlayzed and schematized by the sytem of Chief, Deputy, Assistant and Envoy. The basic formula should be analyzed and schematized by the combination of formula, adding and removing the ingredients. Analyzing Agastache Powder to Rectify the Ki into the system of Chief, Deputy, Assistant and Envoy shows the following: chief herb is Agastaches Herba; deputy herb is Perillae Folium and Angelicae dahuricae Radix; assistant herb is Pinelliae Rhizoma preparatum, Magnoliae officinalis Cortex, Citri reticulatae Pericarpium, Arecae Pericarpium, Platycodi Radix, Atractylodis macrocephalae Rhizoma, Poria, and envoy herb is Glycyrrhizae Radix preparata, Zingiberis Rhizoma recens, Jujubae Fructus.
\end{abstract}


Conclusions : In conclusion, it is believed that the formula education at colleges of Korean medicine would be effectively achieved if it is processed according to the standardized formula analysis and its rule about individual formula that is to be decided.

Keyword : Specific discussions, Formula analysis, Agastache Powder to Rectify the Ki, Formula science, Formula education

$$
\text { I. 서 론 }
$$

방제학 교재는 총론과 각론으로 편찬할 수 있 다. 방제학총론에 대한 편집체제 ${ }^{1}$ 는 이미 발표 하였기 때문에 방제학각론에 대한 편집체제는 어떻게 하는 것이 방제학교육을 효율적으로 할 것인지에 대해서 검토하고자 한다. 그러나 방제 학각론의 분류체제에 대해서는 학자마다 이견이 존재하기 때문에 별도로 연구할 필요가 있고, 여기에서는 방제학각론에 수재할 개별 방제에 대하여 살펴보고자 한다. 방제학각론의 개별방 제는 【出典】・【命名】・【組成】・【用法】・【劑

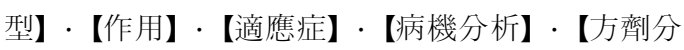
析】・【現代解釋】 ・【臨床應用】・【注意事項】 【源流發展】・【難題解說】・【拔萃文獻】・【醫 案】・【臨床報告】・【燕理作用】・【附方】 과 【參考文獻】 의 20 개 항목으로 정하여 서술해 볼 수 있는데, 이들 항목중에서 특히 【方劑分 析】 에 대한 학자들의 이견이 존재하므로 곽향 정기산을 실례로 들어 바람직한 방제학각론 교 재편찬에서 개별방제의 항목중 방제 配伍분석의 표준안을 제안하고자 한다.

\section{II. 연구방법}

본 연구에서 方劑配伍의 분석대상으로 한 방

\footnotetext{
*교신저자 : 신순식, 부산시 부산진구 양정2동 산45-1 동의 대학교 한의과대학 방제학교실$$
\text { -Tel : 051-850-7414 }
$$$$
\text { ·E-mail : ssshin@deu.ac.kr }
$$

•접수 2013/06/01
}

제는 『太平惠民和劑局方』卷 2 에 나오는 蕉香 正氣散으로 하였다:

“治傷寒頭疼，憎寒壯熱，上喘咳嗽，五勞七傷， 八般風痰，五般膈氣，心腹冷痛，反胃嘔惡，氣瀉 霍亂，臟腑虛鳴，山嵐瘴瘧，遍身虛腫；婦人産前. 産後, 血氣刺痛; 小兒疳傷, 乎皆治之.

大腹皮 获苓 (去皮) 白芷 紫蘇 (去土. 各一兩) 陳樀皮 (去白) 苦梗 白术 厚朴(去粗皮, 薑汁製) 牛夏麯 甘草(采. 各二兩) 蕉香 (去土, 三兩)

上爲細末，每服二錢，水一盏，薑錢三片，霖一 枚，同煎至七分，熱服。如要出汗，衣被蓋，再煎 㚏服.” ${ }^{2}$

한국과 중국에서 발간되어 흔히 보는 27 종의 방제학서를 대상으로 蕉香正氣散의 조성약물의 配伍분석을 조사하였다 (Table 1).

곽향정기산의 方劑配伍는 君臣佐使論 ${ }^{3)}$, 七情配 伍 $^{4)}$ 와 氣味藥性論 ${ }^{5)}$ 등 방제학의 전통적인 정통 이론으로 분석하였다.

Table 1. Formula Science Books Include Agastache Powder to Rectify the $K i$ in Korea and China

\begin{tabular}{|c|c|}
\hline 구분 & 방제학서 \\
\hline $\begin{array}{l}\text { 한국 } \\
\text { (3종) }\end{array}$ & $\begin{array}{l}\text { 『東醫臨床方劑學』・『四像體質醫學論』・『圖解增補 東 } \\
\text { 醫方劑와 處方解說』 }\end{array}$ \\
\hline $\begin{array}{l}\text { 중국 } \\
(24 \text { 종 })\end{array}$ & 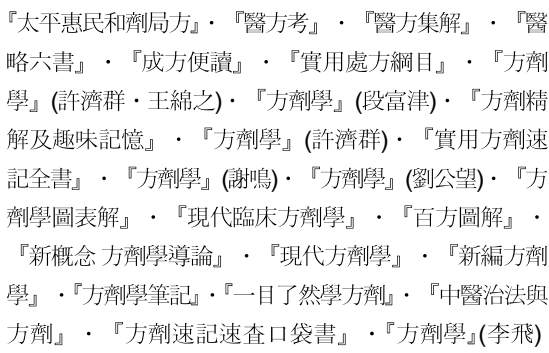 \\
\hline
\end{tabular}




\section{III. 결 과}

\section{1. 醫方考』 의 方解}

吳昆은 “內傷과 外感으로 霍亂이 된 자는, 곽 향정기산으로 주관하게 한다. 內傷인 경우는 그 속을 고르게 해야 한다. 蕉香·白术·获苓·陳皮·甘草. 牛夏·厚朴桔梗과 大腹皮는 모두 속을 고르게 하 는 약물이다. 속을 고르게 하면 內에서 氣가 바르 게 된다. 外感인 경우는 그 表를 트이게 해야 한 다. 紫蘇葉과 白芷가 表를 트이게 하는 약물이다. 表를 트이게 하면 外에서 氣가 바르게 된다. 두 약물은 表에 있는 風寒을 없애고 또한 發越脾氣 하는 작용이 있으므로 “正氣”라고 한 것이다." ${ }^{\left.{ }^{6}\right)}$ 라 고 하여 蕉香正氣散의 조성약물을 君臣佐使論으 로 분석하지 않았다.

\section{2. 醫方集解』의 方解}

汪昂은 “곽향정기산은 手太陰經과 足陽明經의 약물이다. 蕉香은 그 性味가 辛溫하여 理氣和中 과 辟惡止嘔의 작용이 있으며, 兼하여 表裏를 모두 치료하므로 君藥이 된다. 紫蘇葉·白芷와 桔梗은 散寒利膈의 작용이 있고 이들을 佐藥으로 하여 表邪를 發散시키는 작용이 있다. 厚朴과 大腹皮는 行水消滿의 작용이 있고, 滳皮와 牛夏는 散逆除 痰의 작용이 있으며 이들을 佐藥으로 하여 疏裏滯 의 작용이 있다. 获苓·白术과 甘草는 益脾去濕의 작용이 있어서 正氣를 도와 토使藥이 된다. 正氣가 通暢하면 邪逆은 저절로 없어지게 된다." ${ }^{{ }^{7}}$ 라고 하여 蕉香正氣散의 조성약물을 君臣佐使論으로 분석하였다. 君藥은 蕉香이고, 臣藥은 获苓 - 白 术과 甘草이며, 佐藥은 紫蘇葉 · 白芷 - 桔梗 - 厚 朴・ 大腹皮 $\cdot$ 滳皮와 牛夏이고, 使藥은 甘草이다.

\section{3. 醫略六書』의 方解}

徐大椿은 “脾胃가 고르지 않고 暑濕에 감염되 면 中氣는 運化기능을 할 수가 없다. 그러므로 身 熱이 풀리지 않고 腹滿吐瀉가 생긴다. 蕉香은 快 胃社暑의 작용이 있고, 蘇葉은 解表散濕의 작용이 있으며, 大腹皮는 䄉湯滯氣의 작용이 있다. 옵 术은 健脾元의 작용이 있고, 厚朴은 散滿除濕의
작용이 있으며, 牛夏는 醒脾燥濕의 작용이 있다. 陳皮는 利中의 작용이 있고, 获苓은 渗濕邪의 작 용이 있으며, 白芷는 散陽明之濕의 작용이 있다. 桔梗은 利太陰之氣의 작용이 있고, 甘草는 甘緩中 州의 작용이 있으며, 生薑과 大東는 調和營衛의 작용이 있다. 곽향정기산은 調中散邪의 작용이 있 는 방제로 感冒暑濕을 전문적으로 치료하는 방제 이다. 이 방제는 물이 맞지 않아 생긴 병을 치료 하는데 또한 강점이 있어 扶土勝濕의 뜻이 있 다." ${ }^{8)}$ 라고 하여 蕉香正氣散의 조성약물을 君臣佐 使論으로 분석하지 않았다.

\section{4. 『成方便讀』 의 方解}

張秉成은 “저 四時不正之氣와 瘴嵐·滤疾等登은 모두 中氣不足에 의하여 바야흐로 걸리게 된다. 中氣가 虛한 사람은 매번 痰滯가 많다. 그런 뒤에 無形之氣에 有形之痰을 껴서 서로 뭉쳐 질환에 걸린다. 그러므로 곽향정기산은 白术과 甘草의 補 土建中 작용이 있는 것이고, 곧이어 半夏·陳皮와 获苓으로 化痰祛濕의 작용을 이어나간다. 그러나 不正之氣는 口鼻에서 안으로 들어간 것이 많으므 로 다시 桔梗의 宣肺 작용과 厚朴의 本胃 작용으

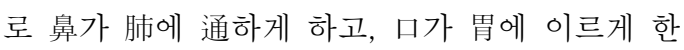
다. 蕉香.紫蘇葉과 白芷는 모두 芳香辛散의 약물 로 다 發表宣裏와 辟惡社邪의 작용을 한다. 大腹 皮만 脾胃에 들어가서 行水散滿과 破氣寬中의 작 용을 한다. 여기에 生薑과 大雨를 넣어 營衛를 조 화시키고 津液이 이르게 하며, 和中達表의 작용 을 하게 한다. 이렇게 되면 邪氣가 물러나지 않고 氣가 바르지 않겠는가?”8)라고 하여 蕉香正氣散의 조성약물을 君臣佐使論으로 분석하지 않았다.

\section{5. 㖦醫臨床方劑學』의 方解}

尹吉榮은 “本方은 平陳湯을 牛減하고 蕉香. 蘇 葉・白芷・大腹皮 $\cdot$ 桔梗을 加하여 蕉香을 君藥으 로 한 方劑로 不換金正氣散의 加味方도 된다. 蕉 香은 辛溫으로 理氣・和中・辟惡 - 止㗐犃㗁 表裏 를 並治하므로 君藥이 되고 蘇葉・白芷・桔梗은 散寒利膈하니 佐로 하여 表邪를 散하고 厚朴 - 大 腹皮는 行水消滿하고 樀皮・牛夏는 散逆除痰하니 
佐로하여 裏氣를 疎하고 获苓・白术・甘草는 益 脾去濕하여 正氣를 補하니 臣使가 되어 正氣가 通暢하여 脾胃中州가 一和하면 客邪가 自除한다. 傷寒陰症과 身痛不分表裏에 本力으로 導引하면 不致變動한다. 그러나 太陽傷寒의 頭痛·發熱 骨節痛과는 全無相干이니 는⺆하면 비록 汗出하 여도 解하지 않고 壞登을 變成한다." ${ }^{9}$ 라고 하여 蕉香正氣散의 조성약물을 君臣佐使論으로 분석하지 않고, 平胃散과 二陳湯의 용량을 반으로 줄이고 蒼术을 白术로 바꾸고 烏梅는 빼고, 다시 蕉香 - 紫 蘇葉 - 白芷 · 大腹皮와 桔梗을 넣어 蕉香을 君藥 으로 한 方劑로 不換金正氣散에서 蒼术을 白术로 바꾸고, 다시 紫蘇葉 - 白芷 - 大腹皮 $\cdot$ 桔梗 $\cdot$ 获苓 과 大雨를 넣은 不換金正氣散의 加減方으로 분석 하였다.

\section{6. 『四象體質醫學論』의 方解}

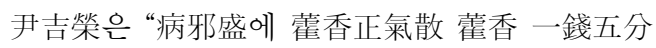
紫蘇葉一錢蒼术白术牛夏陳皮青皮大腹皮桂

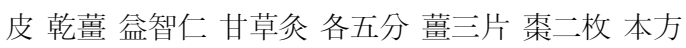
은 和劑局方 蕉香正氣散에서 桔梗 - 白芷 - 厚朴 . 获苓을 除하고 蒼术・靑皮・桂皮 - 乾畺 - 益智仁 을 加한 것이다. 厚朴을 除한 것은 一失이며 盆智 仁은 반드시 必要한 것은 아니다. 少陽人은 利水 를 必要로 하며 少陰人은 利水를 忌하므로 获苓 을 除하고 下行하는 靑皮와 泄하면서도 氣를 傷 치 않고 收하면서도 䔨滯치 않는 益智仁을 加하 여 获苓의 利水導氣하는데 代置한 것이요, 靑皮 가 있어 破氣下行하므로 厚朴을 除한 것이요, 桔 梗·白芷는 上行하여 肺經風寒을 治하는 藥物이니 胃腸을 編主할 때는 必要가 없으므로 除한 것이 다. 그러나 获苓은 泄하면서도 氣를 傷치 않고 收 하면서도 雍滯하지 않으니 구태여 厚朴 - 获苓을 除하고 益智仁・靑皮를 쓸 必要가 없다. 過利를 꺼린다면 行水하는 大腹皮를 除하는 것이 오히려 좋을 것이다. 本方은 表登・裏登・胃腸不和・風 寒 - 溫熱 - 痰創 - 大便不利 - 小便不利 - 一切病邪 가 盛한데 用하는 通治方이니 그 妙는 加減變通 에 있다." ${ }^{10)}$ 라고 하여 蕉香正氣散의 조성약물을 君臣佐使論으로 분석하지 않고, 『太本惠民和劑
局方』의 蕉香正氣散에서 桔梗 - 白芷 - 厚朴과 获

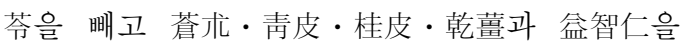
넣어 少陰人 蕉香正氣散으로 변화한 것을 분석하 였다.

7. 『圖解增補 東醫方劑科處方解說』 의 万解 尹用甲은 “蕉香을 君으로 한 不換金正氣散에 二 陳湯, 蘇葉, 白芷, 大腹皮, 桔梗을 配合한 方劑로 볼 수 있다. 不換金正氣散은 外感內傷, 傷寒陰登 에 使用하는 基本方이며, 二陳湯은 痰飲을 없애준 다. 蘇葉은 發散과 理氣를 돕고, 白芷는 止痛, 大 腹皮는 下行하고 桔梗은 上行하여 ㅏㅏ요을 돕는다. 따라서 本方은 不換金正氣散의 效能에 發散, 祛 痰, 理氣, 止痛, 升降作用을 補强한 方劑로 外感과 內傷을 兼하여 表裏의 구분이 어려울 때 活用하는 方劑이다.” (Fig. 1) ${ }^{11)}$ 라고 하여 蕉香正氣散의 조 성약물을 君臣佐使論으로 분석하지 않고, 不換金 正氣散에 二陳湯을 合方하고 여기에 蘇葉 · 白芷 · 大腹皮와 桔梗을 넣은 방제로 분석하였다.

\section{8. 『實用處方綱目』의 万解}

何倫은 “곽향정기산은 解表와 治裏의 작용이 있어 表裏兩解이 治法을 구체화하였다. 비교하여 말하면, 化濕和胃의 작용에 중점을 두었고, 解表 散寒의 藥力은 약간 떨어진다. 化濕和胃의 작용 은 本胃散과 二陳湯에 사용된 약물에 집중된다. 방제 중에 紫蘇葉·白芷와 桔梗은 昇하는 작용이, 获苓・斗夏와 大腹皮는 降하는 작용이, 蕉香・紫 蘇葉诿 厚朴 등은 社邪의 작용이, 获苓 - 白术 甘草와 大霖는 扶正의 작용이 있으나 祛邪의 작 용이 위주이다. 이것은 또한 昇淸降濁과 扶正社 邪의 治法을 구체화한 것이다. 모든 약물을 조화 롭게 사용하면 風寒의 病邪는 밖에서 풀리고 濕 濁은 안에서 없어지며, 清氣는 오르고 濁氣는 내 리며 氣機는 고르게 이르러서 모든 병증이 스스 로 낫게 된다. ${ }^{12)}$ 라고 하여 蕉香正氣散의 조성약 물을 君臣佐使論으로 분석하였다. 君藥은 蕉香이 고, 臣藥은 牛夏麰과 厚朴이며, 佐藥은 紫蘇葉 白芷・陳皮 - 大腹皮 - 白术 - 获苓과 桔梗이고, 使 藥은 甘草 - 生薑과 大霖이다. 도해에서는 病機분 


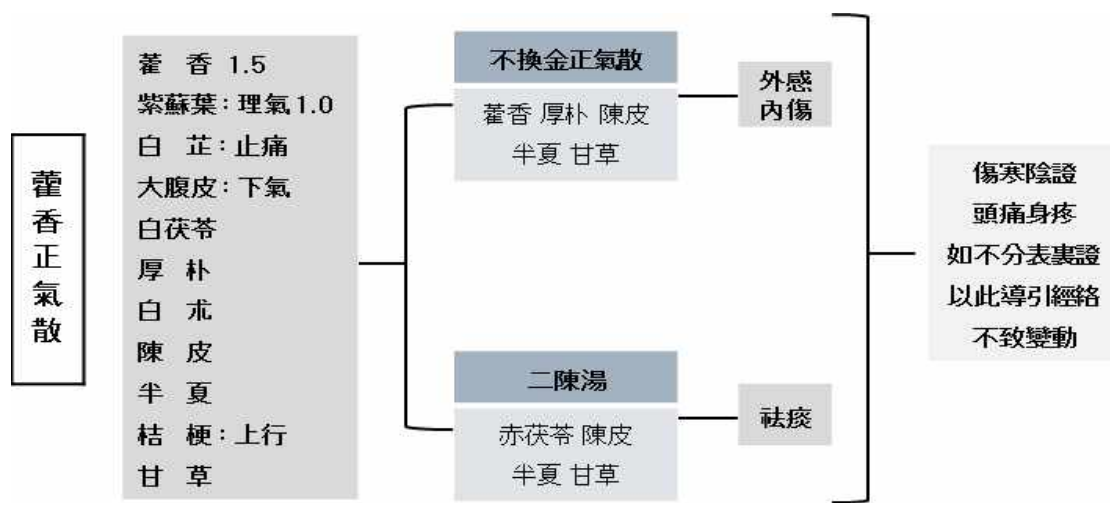

Fig. 1. Analysis using basic formula in Diagram for Korean formula and it's interpretation

석과 方劑配伍분석을 같이 연결하여 제시하였다 (Fig. 2).

\section{9. 『方劑學』 의 方解}

許濟群과 王綿之는 “곽향정기산은 外感風寒과 內傷濕濁으로 생긴 霍亂吐瀉를 치료하는 常用方 이다. 風寒의 病邪가 밖에서 묶고 衛陽이 閷滯되 면 惡寒發熱과 頭痛이 생기고, 濕濁이 안에서 막 히고 氣機가 원활하게 순환하지 않으면 胸膈滿悶 과 脘腹疼痛이 생기며, 濕滯脾胃하여 昇淸降濁의 기능이 정상적으로 이루어지지 않으면 上吐下鴧 가 생긴다. 外散風寒과 內化濕濁의 작용이 있고,
兼하여 理氣和中의 작용이 있는 治法이 적합하다. 방제 중의 蕉香은 용량이 홀로 重하여 君藥이 된 다. 그 辛溫한 性味를 취하여 表에 있는 風寒의 病邪를 풀고, 그 芳香性이 있어 裏에 있는 濕濁의 病邪를 없애며, 또한 辟穢和中과 昇清降濁의 작용 이 있어 霍亂을 치료하는 主藥이다. 『藥品化義』 에서는 '其氣芳香, 善行胃氣, 以此調中, 治嘔吐霍 亂; 以此快氣, 除穢惡㾂悶. 且香能和合五藏, 若脾 胃不和，用之助胃而進领食，有醒脾開胃之功。辛 能通利九竅，若嵐瘴時疫用之，不使外邪內侵，有 主持正氣之力.'이라고 하였다. 紫蘇葉과 白芷의 辛香發散 작용을 配伍하면 蕉香의 外解風寒의 작
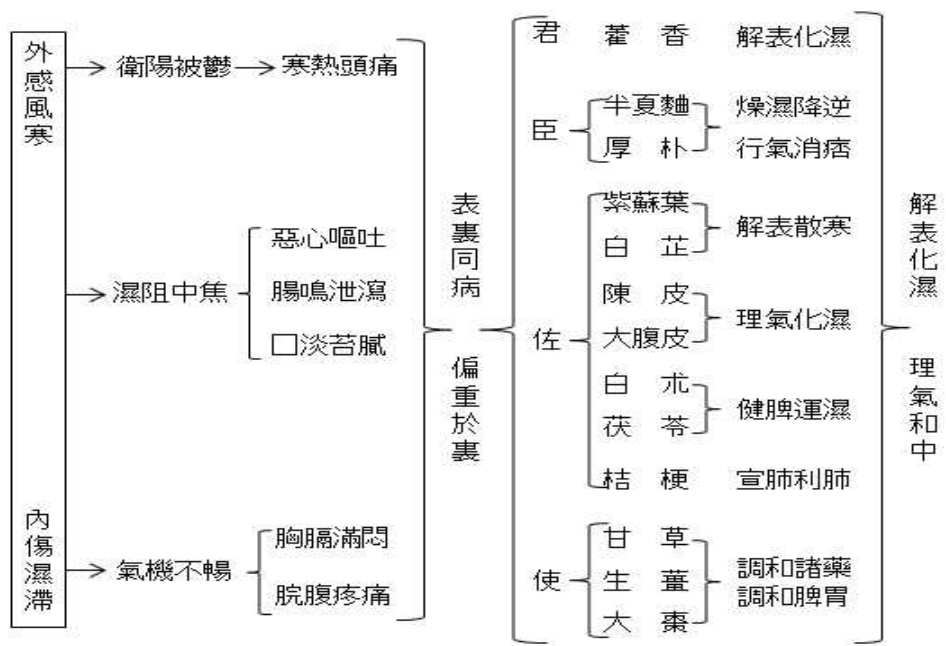

Fig. 2. Analyzing formula in Compendium of practical formula 
용과 兼하여 芳化濕濁의 작용을 돕는다. 牛夏麳 과 陳皮는 燥濕和胃와 降逆止嘔의 작용이 있고, 白术과 获苓은 健脾運濕과 和中止瀉의 작용이 있 으며, 厚朴과 大腹皮는 行氣化濕과 暢中除満의 작용이 있고, 桔梗은 宣肺利膈의 작용이 있어 解 表의 작용에 이롭고 化濕의 작용에 보탬을 준다. 生薑·大霖와 甘草는 調和脾胃의 작용과 藥性을 조 화시키는 작용이 있다. 이상을 종합하면 表裏雙 解·昇淸降濁·理氣和中과 辟惡除邪의 작용이 있어 風寒의 病邪를 밖으로 흐트러트리고, 濕濁의 病 邪는 안에서 없애며, 氣機는 원활하게 순환하게 하고 脾胃가 調和되면 寒熱吐鴧의 諸登이 스스로 낫게 된다.

곽향정기산은 化濕和胃의 작용에 중점이 있고, 解表散寒의 藥力은 조금 떨어지며, 여름철에 傷濕 感寒과 脾胃不和者에게 가장 적합하다. 만일 山嵐 瘴氣에 感觸되고 水土不服하여 寒熱吐瀉가 생긴 자는 이 방제를 사용하여 化濁辟穢快氣和中의 작 용과 調理脾胃의 작용을 얻으면 모두 치료하게 된 다. 근대에는 濕傷脾胃와 外感風寒으로 생긴 急性

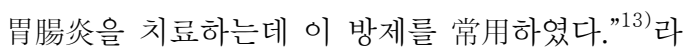
고 하여 蕉香正氣散의 조성약물을 君臣佐使論으로 분석하지 않았으나, 조성약물 간의 燕物配伍는 방 제학의 전통이론을 이용하여 합리적인 분석을 내 놓고 있다.

\section{0. 㕫劑學』의 方解}

段富津은 “곽향정기산은 霍亂吐瀉를 치료하는 데, 바로 이 병증은 外感風寒과 內傷濕滯로 생긴 다. 風寒의 病邪에 감염되어 밖을 묶고 衛陽이 䘖粦 滯되면 惡寒發熱이 생기고, 濕濁이 안에서 막히고 脾胃가 不和하며 昇降의 기능이 정상적으로 이루 어지지 않으면 上吐下瀉와 脘腹疼痛이 생긴다. 外 散風寒과 內化濕濁의 작용이 있고, 兼하여 和中理 氣의 작용이 있는 治法이 적합하다. 방제 중의 蕉 香은 용량이 偏重되어 있고 그 辛散한 性味를 취하 여 表에 있는 風寒의 病邪를 풀고, 그 芳香으로 裏 에 있는 濕濁을 없애며, 또한 辟欌和中과 昇淸降濁 의 작용이 있으므로 본 방제에서 蕉香이 君燕이 된 다. 紫蘇葉과 白芷의 辛香發散 작용을 配伍하면 蕉
香의 外散風寒의 작용과 兼하여 芳化濕濁의 작용 을 돕는다. 牛夏秚과 陳皮는 燥濕和胃와 降逆止嘔 의 작용이 있고, 白术과 获苓은 健脾運濕과 和中止 瀉의 작용이 있으며, 厚朴과 大腹皮는 行氣化濕과 暢中除滿의 작용이 있고, 桔梗은 宣肺利膈의 작용 이 있어 解表의 작용에 보탬이 되고 그 化濕의 작 용을 도와준다. 生薑·大雨와 甘草는 營衛를 調和하 고 調藥和中의 작용이 있다. 방제 전체를 종합하면 表裏雙解·化濕辟檅·昇清降濁과 理氣和中의 작용이 있어 外散風寒·內化濕濁과 氣機의 순환을 원활하게 하고 脾胃를 調和시키면 寒熱吐鴧가 스스로 낫게 된다. 만일에 山嵐瘴氣에 感觸되고 水土不服한 者 는 또한 이 방제로 化濁辟穢와 快氣和中의 작용이 있어 모두 치료된다. ${ }^{14)}$ 라고 하여 蕉香正氣散의 조 성약물을 君臣佐使論으로 분석하지 않았으나, 조 성약물 간의 燕物配伍는 방제학의 전통이론을 이 용하여 합리적인 분석을 내놓고 있다.

\section{1. 『方劑精解及趣味記憶』 의 万解}

劉學文과 湯慶祥은 蕉香正氣散의 조성약물을 君 臣佐使論으로 도해분석하였는데, 病機분석과 方劑 配伍분석을 같이 연결하여 제시하였다 (Fig. 3) ${ }^{15}$. 君藥은 蕉香이고, 臣藥은 紫蘇葉 - 白芷 - 牛夏麯 · 陳皮 - 白术과 获苓이며, 佐藥은 厚朴・大腹皮와 桔 梗이고, 使藥은 甘草·生薑과 大霖이다.

\section{2.『方劑學』의 方解}

許濟群은 "곽향정기산은 霍亂吐瀉를 치료하는 常用方이다. 그 병증은 外感風寒과 內傷濕滯로 清 濁이 분리되지 않고 너푼거리고 어지럽혀 생긴다. 밖에서 風寒의 病邪에 감염되고 衛陽이 鬱滯되면 惡寒發熱과 頭痛이 생기고, 濕濁이 안에서 막히고 氣機가 원활하게 순환하지 않으면 胸膈滿悶과 脘 腹疼痛이 생기며, 濕滯腸胃하면 清氣는 오르지 못 하고 濁氣는 내려가지 못하여 霍亂吐鴧가 생긴다. 舌苔白倵는 바로 濕䌚의 象이다. 外散風寒과 內化 濕濁의 작용이 있고, 争하여 和中理氣의 작용이 있는 治法이 적합하다. 방제 중의 蕉香은 용량이 偏重되어 있고 그 辛散風寒의 작용과 芳香化濁의 작용이 있으며 兼하여 昇淸降濁의 작용이 있어 霍 


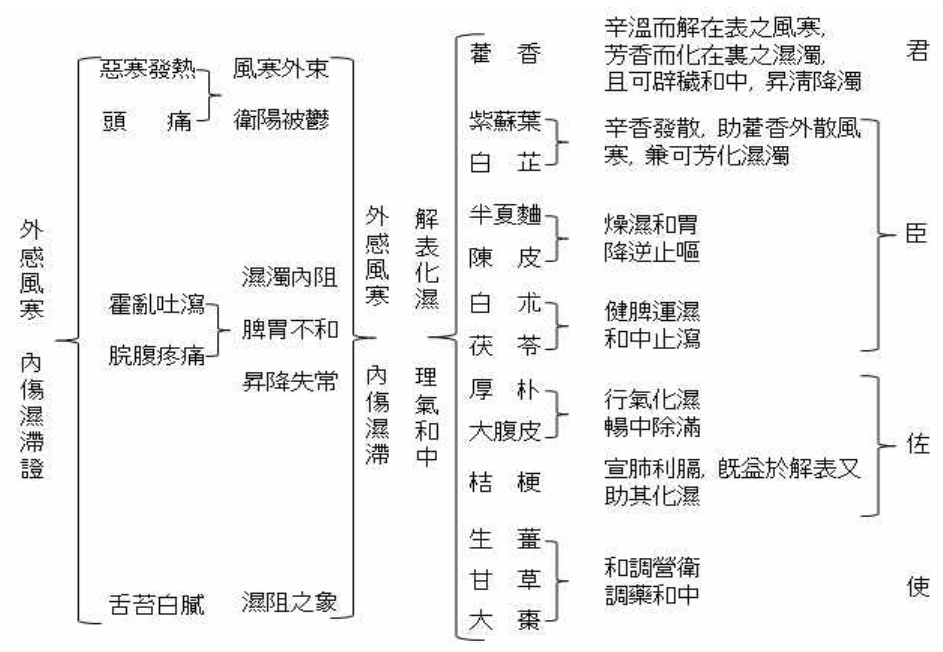

Fig. 3. Analyzing formula in Interpretation in detail and interesting memory for formula

亂을 잘 치료한다. 紫蘇葉과 白芷의 辛香發散 작 용을 配伍하면 蕉香의 外解風寒의 작용과 争하여 芳化濕濁의 작용을 돕는다. 牛夏麳과 陳皮는 燥濕 和胃와 降逆止嘔의 작용이 있고, 白术과 获苓은 健脾運濕과 和中止瀉의 작용이 있으며, 厚朴과 大 腹皮는 行氣化濕과 暢中除滿의 작용이 있고, 桔梗 은 宣肺利膈의 작용이 있어 解表의 작용에 이롭고 化濕의 작용에 보탬을 준다. 生葨·大霖와 甘草는 調和脾胃의 작용과 藥性을 조화시키는 작용이 있 다. 모든 약물을 서로 配伍하게 되면 外散風寒·內 化濕濁·昇淸降濁의 작용이 있고 氣機는 원활하게 순환하게 되면 諸證이 스스로 낫게 된다.

곽향정기산은 化濕和胃의 작용에 중점이 있고, 解表散寒의 藥力은 조금 떨어지며, 여름철에 傷濕 感寒과 脾胃不和者에게 가장 적합하다. 만일 山嵐 瘴瘧과 水土不服者는 또한 本方을 사용하여 치료 한다. 근대에는 濕傷脾胃와 外感風寒으로 생긴 急

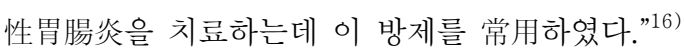
라고 하여 蕉香正氣散의 조성약물을 君臣佐使論으 로 분석하지 않았으나, 조성약물 간의 藥物配伍는 방제학의 전통이론을 이용하여 합리적인 분석을 내놓고 있다.

\section{3. 『實用方劑速記全書』 의 方解}

頓寶生은 蕉香正氣散의 조성약물을 君臣佐使
論으로 도해분석하였는데, 病機분석과 方劑配伍 분석을 같이 연결하여 제시하였다 (Fig. 4) ${ }^{17)}$. 君 藥은 蕉香이고, 臣藥은 牛夏麬과 厚朴이며, 佐藥 은 紫蘇葉 $\cdot$ 白芷 $\cdot$ 陳皮 $\cdot$ 大腹皮 $\cdot$ 白术 $\cdot$ 获苓과 桔梗이고, 使藥은 甘草 - 生畺과 大霖이다.

\section{4. 『方劑學』의 方解}

謝鳴은 “곽향정기산은 外感風寒과 內傷濕濁의 登을 치료하기 위하여 만든 방제이다. 風寒의 病邪가 밖에서 침범하여 안의 衛陽이 막히면 惡 寒發熱과 頭痛이 생기고, 濕濁이 안에서 막히면 脾는 濕困해지고 氣機는 원활하게 순환하지 않 아 昇清降濁의 기능을 잃어버리면 胸膈淽悶·脘

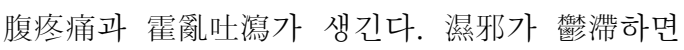
舌苔는 白㖑하게 된다. 본 방제 病證의 病機는 表裏同病이다. 즉, 風寒이 表를 묶어 놓으면 衛

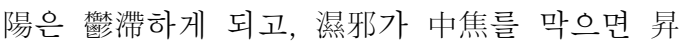
淸降濁의 기능은 잃어버리게 된다. 당연히 外散 風寒·內化濕濁과 兼하여 和中理氣의 작용이 있 는 治法이 적합하다.

방제 중에 蕉香은 그 性味가 辛溫하고 그 氣 는 芳香性이 있다. 밖으로는 表의 風寒을 흐트 러트리고, 안으로는 脾胃의 濕滯를 없애며, 辟 穢和中과 昇清降濁의 작용을 도와준다. 用量은 重用하여 君藥이 된다. 蘇葉과 白芷는 辛香發散 


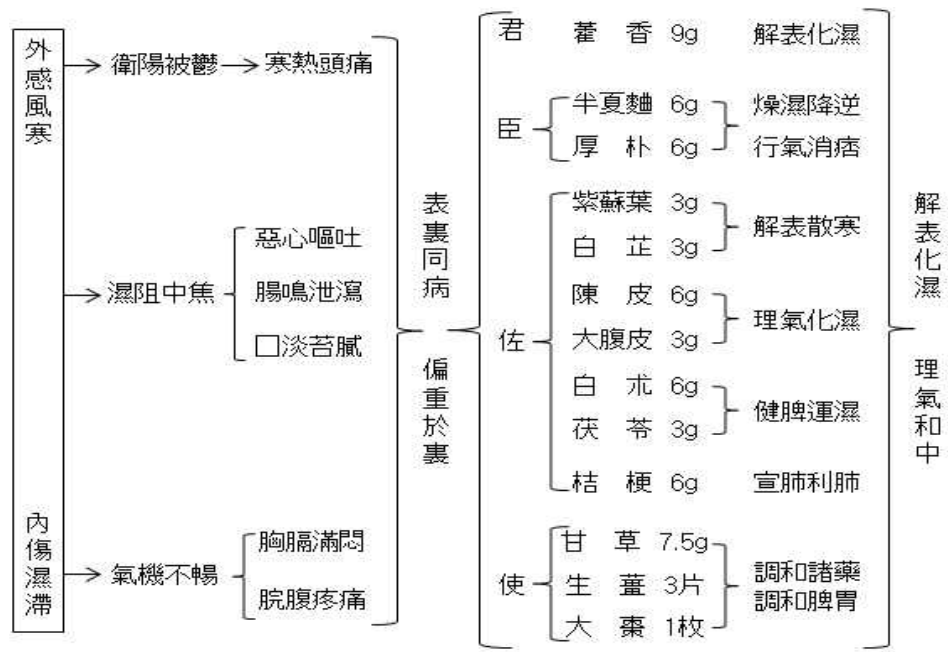

Fig. 4. Analyzing formula in Shorthand encyclopedia for practical formula

의 작용이 있고, 밖으로는 風寒을 푸는 작용이 있 으며, 芳化濕濁의 작용을 康한다. 牛夏䴰과 厚朴 은 燥濕和胃와 降逆止嘔의 작용이 있다. 이 두 그 룹은 蕉香의 解表化濕 작용을 도와 臣藥이 된다.

桔梗은 宣利肺氣의 작용이, 陳皮는 理氣和中 의 작용이, 大腹皮는 行氣消脹의 작용이 있다. 이들 세가지 약물은 三焦氣機를 消脹하여 解表 化濕의 작용을 돕는다. 白术과 获苓은 健脾運濕 과 和中止瀉의 작용이 있어 모두 佐藥이 된다.
生薑·大霖와 采甘草는 健脾和胃와 調和諸藥의 작용이 있어 동시에 佐使藥이 된다. 이상의 모 든 약물을 배합하면 解表化濕과 理氣和中의 작 용이 있게 되어 風寒의 病邪는 풀리고 濕濁은 제거되며 氣機는 고르고 원활하게 순환하며, 昇 淸降濁의 작용이 순조롭게 된다. 결국은 모든 病證이 스스로 없어지게 된다.

配伍 특징은 세 가지이다. 하나는 解表와 疏 裏, 昇淸과 降濁의 작용을 서로 사용하는 것이다.

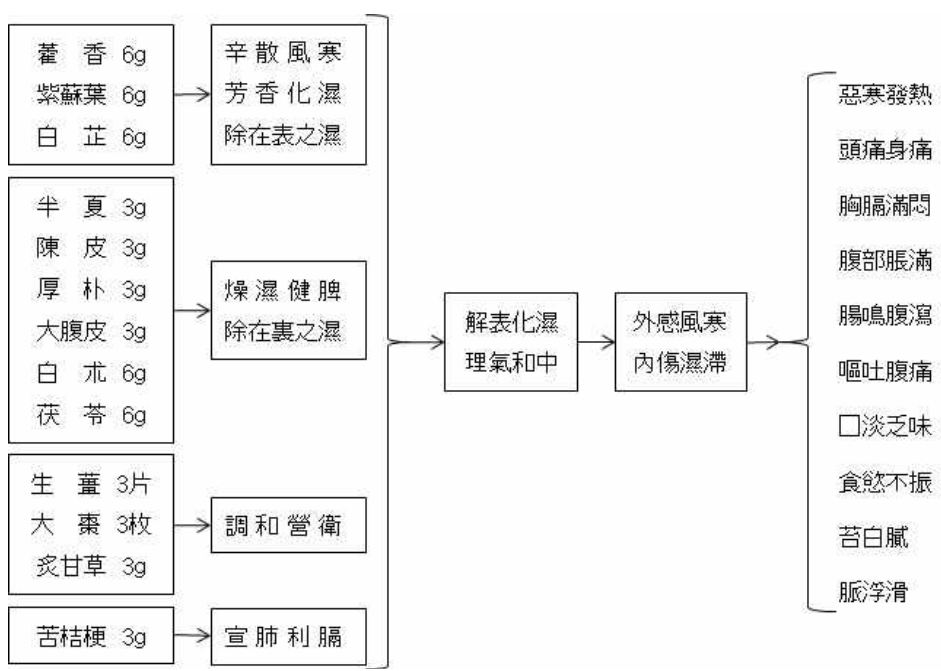

Fig. 5. Analyzing formula in Formula science (Liu Gong Wang) 


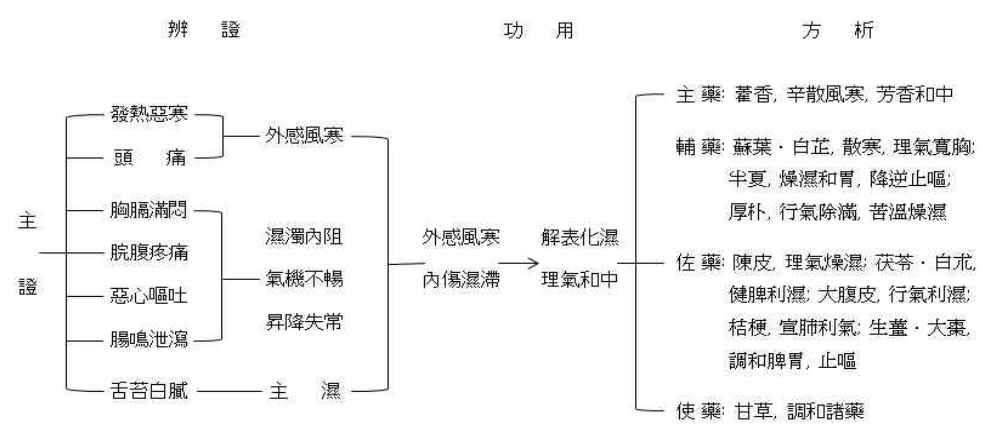

Fig. 6. Analyzing formula in Chart solution for formula science

다른 하나는 標와 本을 같이 고려하고, 扶正祛邪 하며, 解表·祛濕과 補脾의 治法을 결합한 것이

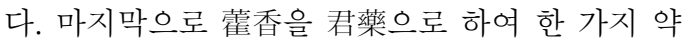
물로 세 가지 작용을 얻었다. 즉, 解表·化濕과 和 中의 작용이다. 본 방제는 表裏를 동시에 치료하 지만 治裏가 위주이고, 昇降을 廉하지만 降이 위주 이며, 標本을 같이 고려하지만 治標가 위주이고, 扶正祛邪가 있지만 祛邪가 위주가 된다." ${ }^{18)}$ 라고 하여 蕉香正氣散의 조성약물을 君臣佐使論으로 분석하였다. 君藥은 雚香이고, 臣藥은 紫蘇葉 白芷・牛夏䴰과 厚朴이며，佐藥은 桔梗・陳皮 · 大腹皮 $\cdot$ 白术과 获苓이고, 使藥은 甘草 $\cdot$ 生薑과 大霖이다.

\section{5. 『方劑學』의 方解}

劉公望은 蕉香正氣散의 조성약물을 君臣佐使 論으로 분석하지 않았으나 조성약물 상호간의 配 伍를 도해분석하였다. 도해는 病機분석과 方劑配 伍분석을 같이 연결하여 제시하였다 (Fig. 5) ${ }^{19)}$.

\section{6. 『方劑學圖表解』의 方解}

李慶業과 楊斌은 蕉香正氣散의 조성약물을 君 臣佐使論으로 도해분석하였는데, 病機분석과 方劑 配伍분석을 같이 연결하여 제시하였다 (Fig. 6) ${ }^{20)}$. 君藥은 蕉香이고, 臣藥은 紫蘇葉・白芷・牛夏麯 과 厚朴이며, 佐藥은 桔梗 ·陳皮 ·大腹皮 · 白术 获苓・生薑斗 大霖이고, 使藥은 甘草이다.

\section{7. 現代臨床方劑學』의 方解}

張民慶은 “곽향정기산은 外感風寒과 內傷濕滯 로 인한 病證을 치료하는 방제이다. 風寒의 病邪 가 밖에서 침범하여 안의 衛陽이 凿滯되면 惡寒 發熱과 頭痛이 생기고, 濕濁이 안에서 막히고 氣 機는 원활하게 순환하지 않으면 胸膈滿悶과 脘腹

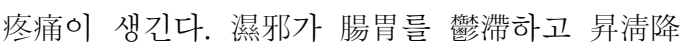
濁의 기능을 잃어버리면 嘔惡瀉泄이 생긴다. 舌 苔白肠는 濕邪의 象이다. 따라서 外散風寒·內化 濕濁과 兼하여 和中理氣의 작용이 있는 治法이 적합하다. 방제 중에 蕉香은 君藥이 되고 辛散風 寒·芳化濕濁과 和胃悅脾의 작용을 한다. 牛夏麳 에는 燥濕降氣와 和胃止嘔의 작용이, 厚朴에는 行氣化濕과 寬胸除滿의 작용이 있고, 紫蘇葉과 白芷는 蕉香의 外散風寒과 康하여 芳香化濕의 작 용을 돕고, 陳皮에는 理氣燥濕과 和中의 작용이, 获苓과 白术에는 健脾運濕의 작용이, 大腹皮에는 行氣利濕의 작용이, 桔梗에는 宣肺利膈의 작용 이, 生葍과 大霖에는 調和脾胃의 작용이 있다. 모 두 佐藥이 된다. 使藥으로서 甘草는 調和諸藥의 작용이 있다. 이상의 약물이 배합되어 방제를 이 루면 風寒은 散하고 濕濁은 化하고 氣機는 通暢 하며 脾胃는 調和하여 諸證은 스스로 낫게 된다. 현대 약리연구에 의하면 저농도 곽향정기산액은 분리한 집토끼 소장에 대하여 이중조절작용이 있 고 고농도에서는 억제작용이 있다. 분리한 십이 지장에서는 뚜렷한 억제작용이 있고, 콜린자극제 로 생긴 장경련에 대항하고, 콜린자극제로 생긴 개와 토끼의 체내 장관의 경련에 대하여 현저한 억제작용이 있다. 그러므로 장경련으로 인한 복 


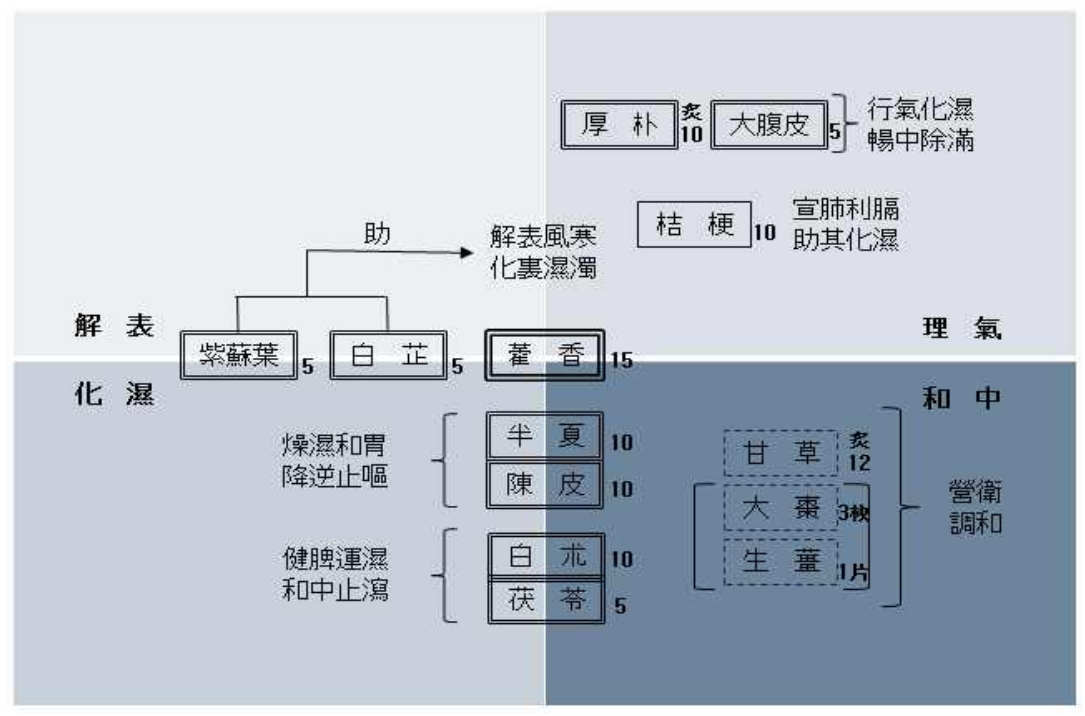

Fig. 7. Analyzing formula in Diagram for one hundred formula

통을 치료한다. 실험과 동시에 관찰하여 보면 곽 향정기산은 위장 평활근에 양호한 解痤작용이 있 지만 담낭과 방광의 평활근에는 수축작용이 없 다. 이상의 약물을 배합하면 解痤과 抗菌 등의 작 용이 있다. ${ }^{21)}$ 라고 하여 蕉香正氣散의 조성약물 을 君臣佐使論으로 분석하였다. 君藥은 蕉香이 고, 臣藥은 없고, 佐藥은 紫蘇葉・白芷·牛夏麯 - 厚朴・桔梗 陳皮 $\cdot$ 大腹皮 $\cdot$ 白术 - 获苓 $\cdot$ 生薑 과 大霖이고, 使藥은 甘草이다.

\section{8. 『百方圖解』 의 方解}

趙中振은 蕉香正氣散의 조성약물을 君臣佐使論 으로 분석하지 않았으나 조성약물 상호간의 配伍 를 도해분석하였다. (Fig. 7) ${ }^{22)}$.

\section{9. 新概念 方劑學導論』의 方解}

嚴永清은 “곽향정기산은 外感風寒과 內傷濕濁 의 登을 목표로 설정한 방제로 外散風寒·內化濕 濁과 廉하여 理氣和中의 작용이 적합하다. 그러 므로 방제 중에 蕉香을 重用하여 君藥으로 하였 다. 그 辛溫한 性味를 취하여 表에 있는 風寒을 푸는 작용이 있고 또한 裏에 있는 濕濁을 芳化하 는 작용이 있으며 辟碝和中과 昇淸降濁의 작용이
있다. 따라서 霍亂吐㴼를 치료하는 要藥이 된다. 紫蘇葉과 白芷는 모두 辛溫發散의 작용이 있는 약물로 雚香이 밖으로 風寒의 病邪를 푸는 작용 을 증강시키고, 안으로는 濕濁을 제거하는 작용 을 한다. 이들은 臣藥이 된다. 紫蘇葉은 解表散寒 과 行氣和胃의 작용이 있고, 白芷는 解表散寒과 社風除濕의 작용이 있다. 佐藥은 牛夏麯·厚朴·陳 皮·大腹皮·桔梗・白术榤 获苓이다. 裏에 濕滯가 있기 때문에 네가지 약물을 佐藥으로 사용한다. 즉, 牛夏䴰에는 燥濕化痰과 和胃止嘔의 작용이 있어 惡心嘔吐를 제거하고, 厚朴에는 行氣化濕과 寬胸止痛의 작용이 있고, 陳皮에는 理氣燥濕과 和中의 작용이 있으며, 大腹皮에는 下氣寬中과 利水消腫의 작용이 있다. 네가지 약물을 같이 배 합하여 사용하면 燥濕行氣와 降逆和胃의 작용이 있게 되고 蕉香과 함께 霍亂吐㴼를 치료한다. 濕 阻氣滯와 脘腹㾂悶脹滿 等登의 치료에 가장 부합 한다. 또한, 桔梗은 宣肺와 利胸膈間之滯氣의 작 용이 있어 㾂悶을 치료한다. 게다가 肺는 水之上 源이고 肺氣의 宣發과 肅降 기능이 정상적으로 작용하면 通調水道의 기능이 원활하게 된다. 桔 梗이 大腹皮와 配伍하면 行氣利水의 작용이 있어 濕邪가 小便으로부터 나가게 된다. 白术과 获苓의 
健脾社濕 작용을 配伍하면 脾胃의 運化기능을 돕 게 된다. 甘草는 使藥으로 모든 약물을 조화시키 는 작용이 있다. 用法 중에 生葨과 大雨를 조금 넣어 脾胃를 調理시키는 작용이 있다. 본 방제의 配伍 특징은 두 가지이다. 하나는 表裏雙解 작용 이다. 辛溫解表藥으로 發散風寒의 작용이 있고, 苦溫化濕藥으로 燥濕理氣和中의 작용이 있다. 다 른 하나는 扶正祛邪의 작용이다. 본 방제는 疏散 表寒과 芳化濕濁하여 社邪시키는 작용이 있다. 또한, 健脾補中하여 扶正시키는 작용이 있다. 따 라서 病邪를 제거해도 正氣를 다치지 않게 되고 正氣를 도와서 病邪를 제거하는데 도움을 주어 양자는 상부상조하게 된다. ${ }^{23)}$ 라고 하여 蕉香正 氣散의 조성약물을 君臣佐使論으로 분석하였다. 君藥은 蕉香이고, 臣藥은 紫蘇葉과 白芷이며, 佐 藥은 牛夏麯 · 厚朴・陳皮 $\cdot$ 大腹皮 $\cdot$ 桔梗 $\cdot$ 白术 과 获苓이고, 使藥은 甘草・生薑과 大霖이다.

\section{0. 現代方劑學』의 方解}

邱德文 등은 “곽향정기산은 방제 중에 蕉香을 重用하여 君燕으로 하였다. 그 辛溫한 性味를 취 하여 表에 있는 風寒을 푸는 작용이 있고, 또한 그 芳香性으로 인하여 裏에 있는 濕濁을 化하는 작용이 있으며, 그리고 辟檅和中과 昇淸降濁의 작용이 있다. 따라서 霍亂吐鴧를 치료하는 要藥 이 된다. 紫蘇葉은 그 性味가 辛溫하여 解表散寒 과 行氣和胃의 작용이 있고, 白芷는 그 性味가 辛 溫하여 解表散寒과 祛風除濕의 작용이 있다. 紫 蘇葉과 白芷는 모두 辛香發散의 작용이 있는 약 물로 蕉香이 밖으로 風寒의 病邪를 푸는 작용을 증강시키고, 동시에 안으로는 濕濁을 제거하는 작용을 한다. 이들은 臣藥이 된다. 裏에 濕滯가 있으므로 牛夏에는 燥濕化痰과 和胃止嘔의 작용 이 있어 惡心嘔吐를 제거하고, 厚朴에는 行氣化 濕과 寬胸止痛의 작용이 있고, 陳皮에는 理氣燥 濕과 和中의 작용이 있으며, 大腹皮에는 下氣寬 中과 利水消腫의 작용이 있다. 牛夏·厚朴·陳皮와 大腹皮의 네가지 약물을 같이 배합하여 사용하면 燥濕行氣와 降逆和胃의 작용이 있게 되고, 蕉香 과 함께 霍亂吐瀉를 치료한다. 濕阻氣滯와 脘腹
满悶 等의 치료에 가장 적합하다. 또한, 桔梗은 宣肺와 利胸膈間之滯氣의 작용이 있어 㾂悶을 치 료한다. 게다가 肺는 水之上源이고 肺氣의 宣發 과 肅降 기능이 정상적으로 작용하면 通調水道의 기능이 원활하게 된다. 桔梗이 大腹皮와 配伍하 면 行氣利水의 작용이 있어 濕邪가 小便으로부터 나가게 된다. 白术과 获苓의 健脾社濕 작용을 配 伍하면 脾胃의 運化기능을 돕게 된다. 이상의 牛 夏·厚朴・陳皮・大腹皮・桔梗・白术斗 获苓의 여덟 가지 약물은 佐藥이 된다. 甘草는 使藥으로 모든 약물을 조화시키는 작용이 있다. 用法 중에 生薑 과 大雨를 조금 넣어 脾田를 調理시키는 작용이 있다. 이상의 모든 약물을 배합하여 사용하면 風 寒은 밖에서 풀리고 惡寒과 發熱은 나가며 氣機 는 通暢하고 胸膈은 펴지며, 脾胃는 調和하면 모 瀉가 멈추고 邪氣가 물러나면 正氣는 편안해지 고, 正氣가 회복되면 邪氣를 방어할 수 있어 함께 解表化濕과 理氣和中의 작용을 거두게 된다.

본 방제의 配伍 특징은 세 가지이다. 하나는 辛溫解表藥으로 發散風寒의 작용이 있고, 苦溫化 濕藥으로 燥濕理氣和中의 작용이 있어 表裏雙解

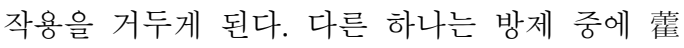
香·紫蘇葉·白芷와 桔梗은 外散風寒과 昇發清陽의 작용이 있고, 厚朴·大腹皮・牛夏栭과 获苓 등은 化濕行氣와 降逆除滿의 작용이 있어 昇淸降濁法 을 구현하였다. 마지막으로 본 방제는 疏散表寒 과 芳化濕濁하여 祛邪시키는 작용이 있고, 또한, 健脾補中하여 扶正시키는 작용이 있다. 따라서 邪氣를 제거해도 正氣를 다치지 않게 되고 正氣 를 도와서 邪氣를 제거하는데 도움을 주어 양자 는 상부상조하여 扶正祛邪의 작용을 거두게 한 다. ${ }^{24)}$ 라고 하여 蕉香正氣散의 조성약물을 君臣 佐使論으로 분석하였다. 君藥은 蕉香이고, 臣藥

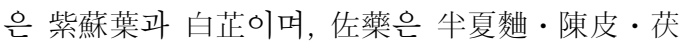
苓・白术 - 厚朴 - 大腹皮와 桔梗이고, 使藥은 甘 草·生薑과 大霖이다.

\section{1. 『新編方劑學』의 方解}

倪誠은 蕉香正氣散의 조성약물을 君臣佐使論으 로 도해분석하였다 (Fig. 8) ${ }^{25)}$. 君藥은 蕉香이고, 


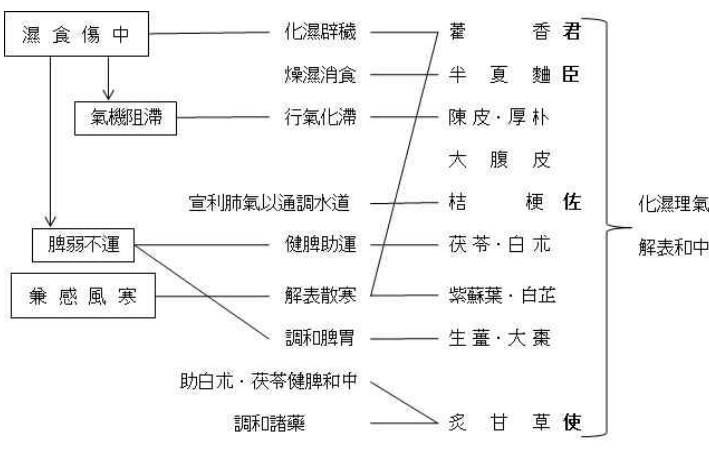

Fig. 8. Analyzing formula in New editing formula science

臣藥은 牛夏麯이며, 佐藥은 陳皮・厚朴・大腹皮 ·桔梗・茯苓・白术・紫蘇葉과 白芷이고, 使藥은 甘草・生畺과 大菓이다.

\section{2.『方劑學筆記』의 万解}

韓旭華는 蕉香正氣散의 조성약물을 君臣佐使論 으로 도해분석하였다 (Fig. 9) ${ }^{26)}$. 君藥은 蕉香이

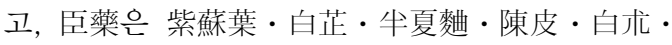
茯苓 - 厚朴 - 大腹皮와 桔梗이며, 佐藥은 甘草 - 生 矒과 大荣이고, 使藥은 없다.

\section{3.『一目了然學方劑』의 方解}

韓旭華는 蕉香正氣散의 조성약물을 君臣佐使論 으로 도해분석하였다 (Fig. 10) ${ }^{27)}$. 君藥은 蕉香이 고, 臣藥은 紫蘇葉과 白芷이며, 佐藥은 牛夏麯 陳皮 - 获苓 - 白术 - 厚朴 - 大腹皮와 桔梗이고, 使 藥은 甘草·生䕬과 大荣이다. 또한, 조성약물의 藥性分析을 제시한 것이 특징이다 (Table 2).

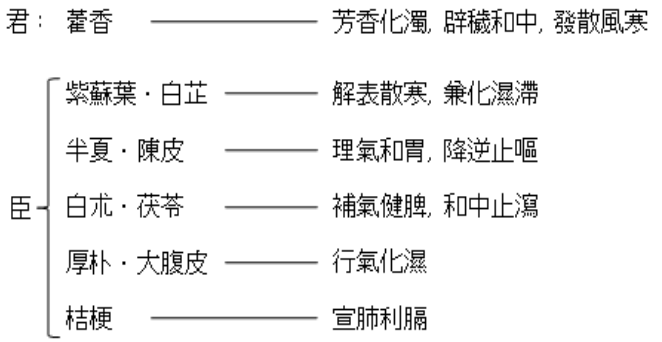

佐: 生增 $\cdot$ 大霖· 甘草一調和脾胃

Fig. 9. Analyzing formula in Notes of formula science

\section{4.『中醫治法與方劑』의 方解}

陳潮租는 “곽향정기산의 병증은 外感과 內傷을 막론하고 결국은 中焦의 運化기능을 잃고 濕은 뭉치고 氣는 막히며 昇淸降濁의 기능을 잃어버려 생긴 것이다. 치료는 반드시 醒脾化濕의 작용으 로 脾의 運化기능을 회복시키고 氣機를 疏暢시키 며 그 昇淸降濁의 기능을 이롭게하고 腠理를 開 泄하여 그 出入을 通하게 한다. 그러면 脾의 運化 기능이 健全하고 津氣는 行하게 되며 昇淸降濁의 기능은 회복하여 모瀉는 그치고 表裏는 조화로워 모든 병증이 낫게 된다. 이 방제는 芳香化濕·利 氣行津·昇清降濁·扶正祛邪와 表裏同治 등 여러 治法을 배합하여 사용하였다. 방제 중에 蕉香은 그 性味가 辛溫하고 理氣和中・辟穢止嘔・外散表邪 와 內化濕濁의 작용을 하여 表裏同治하고 겸하여 調氣行津의 작용이 있어 그 작용이 가장 전체적 이므로 방제 중의 主藥이 된다. 紫蘇葉·白芷와 桔梗은 開宣肺氣와 散寒利膈의 작용이 있어 表證

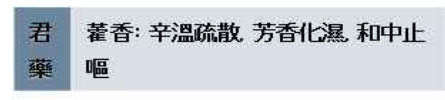

半夏・陳皮: 燥濕理氣。降逆止吐

获苓 - 白术 健脾益氣 - 除濕

厚朴 - 大腹皮: 理氣社蒸 寛胸除沙

桔梗: 宣肺利腷

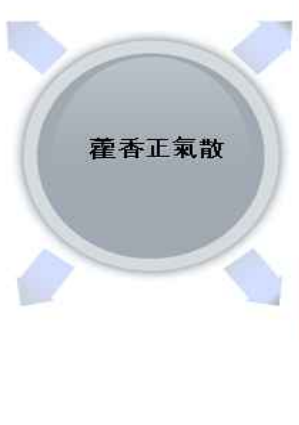

紫蕉葉 - 白芷: 解表散寒
生蓄 - 大妻 - 甘草: 調和脾胃, 調和

諸藥

Fig. 10. Analyzing formula in Sticking out a mile for formula 
Table 2. Analysis Using Properties and Tastes of Materia Medica

\begin{tabular}{|c|c|c|c|}
\hline 藥名 & 性味 & 歸經 & 功效 \\
\hline 藿香 & 辛微溫 & 脾經·胃經·肺經 & 芳香化濕·和中止嘔·發表解暑 \\
\hline 蘇葉 & 辛溫 & 肺經·脾經 & 散寒解表·行氣和胃 \\
\hline 白芷 & 辛溫 & 肺經·胃經·大腸經 & 社風燥濕·通竅止痛·消腫排膿 \\
\hline 大腹皮 & 辛微溫 & 脾經·胃經·大腸經·小腸經 & 下氣寬中·行水消腫 \\
\hline 获苓 & 甘淡平 & 心經·肺經·脾經·腎經 & 利水渗濕·健脾補中.寧心安神 \\
\hline 白术 & 苦甘溫 & 脾經-胃經 & 燥濕利水- 健脾益氣- 固表止汗-安胎 \\
\hline 牛夏 & 辛溫有毒 & 肺經·脾經·胃經 & 燥濕化痰·降逆止嘔·消㾂散結 \\
\hline 陳皮 & 甘辛溫 & 肺經·脾經 & 燥濕化痰·理氣健脾 \\
\hline 厚朴 & 苦辛溫 & 肺經·脾經·胃經·大腸經 & 燥濕化痰·下氣本喘·行氣導滯 \\
\hline 桔梗 & 苦辛本 & 肺經 & 宣肺利咽·祛痰排膿 \\
\hline 甘草 & 甘平 & 心經·肺經·脾經·胃經 & 補脾益氣·緩急止痛·清熱解毒·緩和藥性 \\
\hline
\end{tabular}

이 있으면 蕉香의 疏解表邪의 작용을 돕고, 表證 이 없으면 蕉香의 宣化濕濁의 작용을 돕는다. 厚 朴・大腹皮・陳皮와 牛夏麯은 燥濕運脾·利氣行水 의 작용이 있어 疏裏滯의 작용을 함으로써 돕는 다. 紫蘇葉·白芷·陳皮·厚朴은 芳香性味가 있어 또한 芳化濕濁과 醒脾利氣의 작용을 돕는다. 이 상의 8 종 약물은 모두 醒脾化濕과 調氣行津의 작 용을 나타낸다. 濕濁과 不正之氣가 인체를 다치 게 한 것은 모두 中氣不足으로 인한 것이다. 그러 므로 获苓·白术과 甘草의 健脾祛濕과 扶助正氣의 작용으로 佐를 삼아야 한다. 방제 중에 蕉香·紫 蘇葉과 白芷 등은 解表작용이 있고, 또한 牛夏. 厚朴과 大腹皮 등은 疏裏작용이 있어 表裏兩解法 을 구현하였다. 紫蘇葉·白芷와 桔梗 등은 昇發淸 陽 작용이 있고, 또한 获苓·牛夏와 大腹皮 등은 降泄濁陰의 작용이 있어 昇淸降濁法을 구현하였 다. 紫蘇葉·白芷外 桔梗 등은 上焦에서 辛開肺氣 의 작용이 있고, 厚朴·陳皮와 牛夏 등은 中焦에 서 燥濕芳化의 작용이 있으며 또한 获苓과 大腹 皮는 下焦에서 淡滲利濕의 작용이 있어 三焦同治 法을 구현하였다. 蕉香·紫蘇葉과 白芷 등은 芳香 化濕하고 病因을 제거하며 기능을 회복시키고 疏 通津氣하여 祛邪하는 작용을 한다. 여기에 다시 获苓·白术斗 甘草 등은 健運脾胃하여 扶正의 작 용을 한다. 따라서 扶正祛邪法을 구현한 것이다. 이와같이 配伍하면 없는 게 없이 다 갖추어져 表 裏를 함께 치료하면 寒熱脹滿이 없어지고, 脾의
기능이 회복하고 昇清降濁의 기능이 정상적으로 회복되면 嘔吐泄瀉가 그치며, 邪氣가 없어지면 正氣는 저절로 편안해지고, 正氣가 회복되면 邪 氣는 저절로 물러난다. 그러므로 위의 증후에 제 법 적당하다." ${ }^{28)}$ 라고 하여 蕉香正氣散의 조성약 물을 君臣佐使論으로 분석하지 않았으나, 조성약 물 간의 藥物配伍는 방제학의 전통이론을 이용하 여 합리적인 분석을 내놓고 있다. 특히 三焦同治 法을 제시한 점은 특징이라고 볼 수 있다.

\section{5.『方劑速記速查口袋書』의 方解}

范穎과 馬驥는 蕉香正氣散의 조성약물을 君臣 佐使論으로 도해분석하였다 (Fig. 11) ${ }^{29)}$. 君藥은 蕉香이고, 臣藥은 紫蘇葉・白芷・斗夏䴵斗 厚朴 이며, 佐藥은 桔梗 · 陳皮 $\cdot$ 大腹皮 $\cdot$ 白术斗 获苓 이고, 使藥은 甘草 · 生薑과 大霖이다.

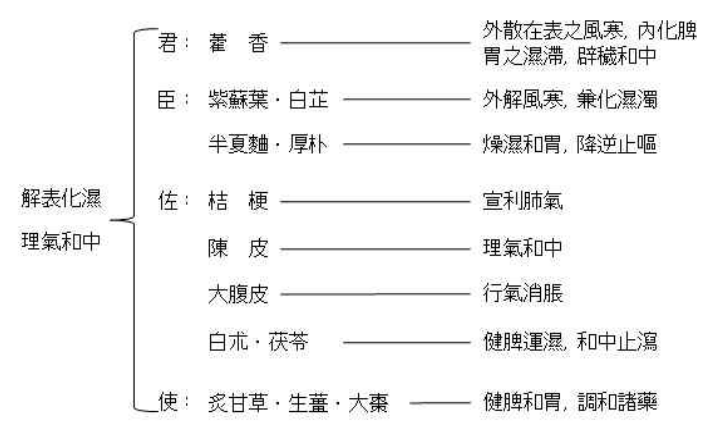

Fig. 11. Analyzing formula in Shorthand speed pocket book for formula 
신순식 : 방제학 공통교재에 수재할 蕉香正氣散의 配伍 분석

26. 㕫劑學』의 方解

李飛는 “곽향정기산은 外感風寒과 內傷濕濁의 證을 목표로 설정한 방제로 外散風寒·內化濕濁과 廉하여 理氣和中의 작용이 적합하다. 그러므로 방제 중에 蕉香을 重用하여 君藥으로 하였다. 그 辛溫한 性味를 취하여 表에 있는 風寒을 푸는 작용 이 있고 또한 裏에 있는 濕濁을 芳化하는 작용이 있으며 辟穢和中과 昇淸降濁의 작용이 있다. 따 라서 霍亂吐瀉를 치료하는 要藥이 된다. 『本草逢 原』卷 2 에서는 '蕉香入手. 足太陰, 芳香之氣, 助脾 醒胃, 故能止嘔逆, 開胃進食, 溫中快氣, 去瘴氣, 止 霍亂, 治心腹痛. 凡時行疫㾖, 山嵐瘴瘧, 用此醒脾 健胃, 則邪氣自無容而㸝矣.'라고 하였다. 蕉香은 어떻게 惡氣를 제거하고 霍亂과 心腹痛을 멈추게 하는 藥力이 있는 것일까? 『本草經解』卷 2 에서 는 ‘蕉香氣微溫, 稟天初春之木氣, ……味辛甘無毒, 得地金土之二味, 入手太陰肺經, 足太陰脾經, 氣味 俱昇. ……濕毒歸脾, 甘可解毒也, 惡氣, 邪惡之氣 也. 肺主氣, 辛可散邪, 所以主之. 霍亂, 脾氣不治揮 霍擾亂也, 芳香而甘, 能理脾氣, 故主之也. 心腹亦 脾肺之分, 氣亂於中則痛, 辛甘而溫, 則通調脾肺, 所以主之也.'라고 하였다. 臣藥은 紫蘇葉과 白芷이 다. 辛溫한 性味가 있는 紫蘇葉은 解表散寒과 行 氣和胃의 작용이 있고, 辛溫한 性味가 있는 白芷 는 解表散寒과 祛風除濕의 작용이 있다. 紫蘇葉과 白芷는 모두 辛香發散의 작용이 있는 약물로 蕉香 이 밖으로 風寒의 病邪를 푸는 작용을 증강시키고 동시에 芳化濕濁의 작용을 兼한다. 佐藥은 牛夏 麴・厚朴・陳皮・大腹皮・桔梗・白术斗 获苓이다. 裏 에 濕滯가 있기 때문에 네가지 약물을 佐藥으로 사용한다. 즉, 牛夏䴵에는 燥濕化痰과 和胃止嘔의 작용이 있어 惡心嘔吐를 제거하고, 厚朴에는 行氣 化濕과 寬胸止痛의 작용이 있고, 陳皮에는 理氣燥 濕과 和中의 작용이 있으며, 大腹皮에는 下氣寬中 과 利水消腫의 작용이 있다. 네가지 약물을 같이 배합하여 사용하면 燥濕行氣와 降逆和胃의 작용 이 있게 되고 蕉香과 함께 霍亂吐瀉를 치료한다. 濕阻氣滯와 脘腹㾂悶脹滿 等登의 치료에 가장 부 합한다. 또한, 枯梗은 宣肺와 利胸膈間之滯氣의 작 용이 있어 痞悶을 치료한다. 게다가 肺는 水之上
源이고 肺氣의 宣發과 肅降 기능이 정상적으로 작 용하면 通調水道의 기능이 원활하게 된다. 桔梗이 大腹皮와 配伍하면 行氣利水의 작용이 있어 濕邪 가 小便으로부터 나가게 된다. 白术과 获苓의 健 脾祛濕 작용을 配伍하면 脾胃의 運化기능을 돕게 된다. 甘草는 使藥으로 모든 약물을 조화시키는 작용이 있다. 用法 중에 生薑과 大東를 조금 넣어 脾胃를 調理시키는 작용이 있다. 본 방제의 配伍 특징은 두 가지이다. 하나는 表裏雙解 작용이다. 辛溫解表藥으로 發散風寒의 작용이 있고, 苦溫化 濕藥으로 燥濕理氣和中의 작용이 있다. 다른 하나 는 扶正祛邪의 작용이다. 본 방제는 疏散表寒과 芳化濕濁하여 祛邪시키는 작용이 있다. 또한, 健 脾補中하여 扶正시키는 작용이 있다. 따라서 病邪 를 제거해도 正氣를 다치지 않게 되고 正氣를 도 와서 病邪를 제거하는데 도움을 주어 양자는 상부 상조하게 된다." ${ }^{8)}$ 라고 하여 蕉香正氣散의 조성약 물을 君臣佐使論으로 분석하였다. 君藥은 蕉香이

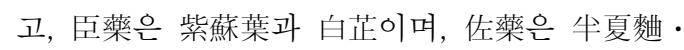
陳皮 - 获苓 - 白术 - 厚朴 - 大腹皮와 桔梗이고, 使 藥은 甘草 $\cdot$ 生薑과 大霖이다.

\section{IV. 고 찰}

한의과대학의 공통교재를 발간할 때 수재할 개 별 방제의 配伍분석을 어떻게 정리하는 것이 합당 한지를 곽향정기산을 실례로 들어 한국과 중국에 서 발간한 방제학서를 중심으로 일관된 원칙에 입 각하여 검토하고 방제학교육에 부합하는 방안을 제시하고자 하였다. 그 분석원칙은 다음과 같다.

첫째는 원 출전의 곽향정기산을 기준으로 해야 한다. 둘째는 곽향정기산을 조성하는 약물의 配伍 는 七情配伍 등 藥對로 분석한다. 셋째는 곽향정 기산의 조성약물의 작용과 적응증 등은 氣味藥性 論으로 분석하고 도표화 한다. 넷째는 곽향정기 산을 君臣佐使論으로 분석하고 도식화 한다. 다섯 째는 곽향정기산을 기본방의 合方加減으로 분석 하고 도식화 한다.

곽향정기산의 원 출전은 『太本惠民和劑局方』 
Table 3. Classifying Formula Science Books into 2 Groups as a Method of Applying the System of Chief, Deputy, Assistant and Envoy to Agastache Powder to Rectify the Ki

\begin{tabular}{|c|c|}
\hline 구분 & 방제학서 \\
\hline $\begin{array}{l}\text { 군신좌사론 적용 } \\
\text { 방제학서 } \\
\text { (14종) }\end{array}$ & 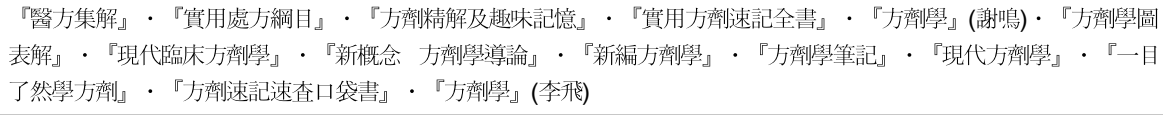 \\
\hline $\begin{array}{l}\text { 군신좌사론 비적용- } \\
\text { 방제학서 } \\
\text { (13종) }\end{array}$ & 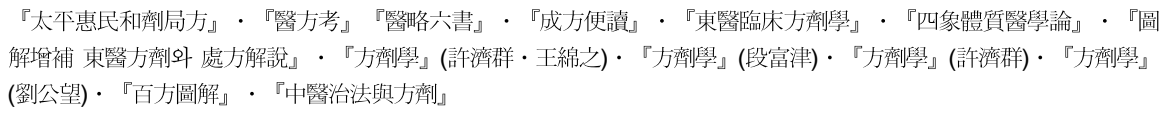 \\
\hline
\end{tabular}

이고, 外感風寒과 內傷濕濁으로 생긴 霍亂吐瀉를 치료하는 常用方이다. 그 조성약물은 大腹皮 获苓 （去皮）白芷紫蘇(去土）各一兩陳樀皮(去白) 苦梗 白术 厚朴(去粗皮, 畺汁製) 牛夏麳 甘草(采) 各 二兩 蕉香(去土) 三兩 薑三片, 菓一枚의 13 종으로 되어 있다.

본 연구에서 방제분석에서 참고한 27 개 방제학 서 중에서 곽향정기산을 군신좌사론을 적용하여 분석한 방제학서는 14 개이고, 적용하지 않은 방제 학서는 13 개이다 (Table 3 ).

곽향정기산의 조성약물인 大腹皮·获苓・白芷・ 紫蘇葉・陳皮・桔梗 . 白术 - 厚朴 - 牛夏麯 - 甘草 - 蕉香 - 生葍 - 大㷊의 13 종을 군신좌사론으로 분 석하여 보면 蕉香을 君藥으로 해야한다는데는 이 견이 없다. 군신좌사론 적용 방제학서 14 종 중에 서 使藥을 설정하지 않은 『方劑學筆記』 및 甘草
一味를 使藥으로 한 『醫方集解』・『方劑學圖表 解』와 現代臨床方劑學』 의 3 방제서 이외의 10 종 방제서는 모두 甘草 - 生瞢과 大荣의 3味를 使 藥으로 하였다. 따라서 蕉香을 君藥으로 甘草 - 生 眐과 大東를 使藥으로 하는 데는 큰 무리가 없어 보인다. 문제는 臣藥과 佐藥을 어떻게 합리적으로 배치하느냐이다. 군신좌사론 적용 방제학서 14 종 중에서는 8종으로 다양하다 (Table 4).

곽향정기산은 外感風寒과 內傷濕濁의 證을 목표 로 설정한 방제로 外散風寒-內化濕濁과 康하여 理氣和中의 작용이 적합하다. 外感風寒에는 外散 風寒의 작용이 있는 紫蘇葉과 白芷를, 內傷濕濁 에는 內化濕濁의 작용이 있는 牛夏麯과 厚朴을, 理氣和中의 작용이 있는 桔梗 $\cdot$ 陳皮 $\cdot$ 大腹皮 $\cdot$ 白 术과 获苓을 사용하는 것이 합리적이다. 문제는

Table 4. Comparison Between Deputy and Assistant as a Method of Combining Ingredients in Agastache Powder to Rectify the Ki

\begin{tabular}{|c|c|c|}
\hline 臣藥 & 佐藥 & 방제학서 \\
\hline 紫蘇葉·白芷 & $\begin{array}{l}\text { 牛夏麴・厚朴・陳皮・大腹皮・桔梗・白术・ } \\
\text { 茯苓 }\end{array}$ & $\begin{array}{l}\text { 『新概念 方劑學導論』・『現代方劑學』・『二 } \\
\text { 目了然學方劑』・『詺學』(李飛) }\end{array}$ \\
\hline 牛夏麥曲・厚朴 & 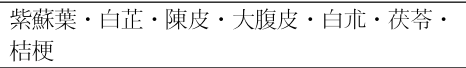 & 『實用處方綱目』・『實用方劑速記全書』 \\
\hline 紫蘇葉·白芷·牛夏䴿·厚朴 & 桔梗 ·陳皮 $\cdot$ 大腹皮 $\cdot$ 白术 $\cdot$ 茯苓 & $\begin{array}{l}\text { 『方劑學』(謝鳴) ・『方劑學圖表解』・『方劑 } \\
\text { 速記速査口袋書』 }\end{array}$ \\
\hline 茯苓·白求·甘草 & $\begin{array}{l}\text { 紫蘍葉・白芷・桔梗・厚朴・大腹皮・橘皮・ } \\
\text { 牛夏 }\end{array}$ & 『醫方集解』 \\
\hline $\begin{array}{l}\text { 紫蘇葉·白芷·牛夏麯・陳皮·白术· } \\
\text { 获苓 }\end{array}$ & 厚朴・大腹皮・桔梗 & 『方齊归青解及趣味記憶』 \\
\hline$x$ & 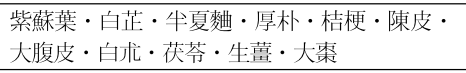 & 『現代臨床方劑學』 \\
\hline 牛夏麴 & $\begin{array}{l}\text { 陳皮 } \cdot \text { 厚朴 } \cdot \text { 大腹皮 } \cdot \text { 桔梗 } \cdot \text { 获苓 } \cdot \text { 白术 } \cdot \text { 紫 } \\
\text { 蘇葉 } \cdot \text { 白芷 }\end{array}$ & 『新編方劑學』 \\
\hline $\begin{array}{l}\text { 紫䒚葉 } \cdot \text { 白芷 } \cdot \text { 牛夏麴 } \cdot \text { 陳皮 } \cdot \text { 白术 } \cdot \\
\text { 获苓·厚朴 } \cdot \text { 大腹皮 } \cdot \text { 桔梗 }\end{array}$ & 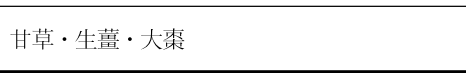 & 『方劑學筆記』 \\
\hline
\end{tabular}


外散風寒·內化濕濁과 理氣和中의 작용 중에서 어느 작용에 중점을 두느냐와 대등한 관계로 보느냐에 따라 紫蘇葉・白芷, 牛夏麯・厚朴과 紫蘇葉・白 芷·牛夏麳・厚朴을 臣藥에 배치하고 나머지를 佐藥에 배치하하는 세 유형이 나오게 된다. 어느 유형을 택하여 기준으로 삼고 配伍분석을 하든지 간에 나머지 두 유형의 배오분석의 가능성을 부가 적으로 제시할 수 있기 때문에 문제가 되지 않는다 고 본다. 곽향정기산의 세 유형에 대한 配伍분석을 그림 12-A, B와 C로 도식화하여 제시하였다.

본 연구에서는 紫蘇葉과 白芷를 臣藥으로 하

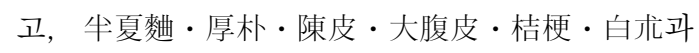
获苓을 佐藥으로 배치하고자 한다.

이상의 논리대로 곽향정기산을 君臣佐使論으 로 배치하면, 君藥은 蕉香이고, 臣藥은 紫蘇葉과

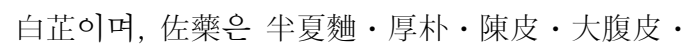
桔梗 - 白术과 获苓이고, 使藥은 甘草 - 生薑과 大 森임을 알 수 있다. 그러면 이에 따라 곽향정기산 의 조성약물을 君臣佐使論, 氣味藥性論과 藥物配 伍 등의 이론에 따라 방제를 분석하고 그 配伍原 理의 특징을 살펴보면 다음과 같다.

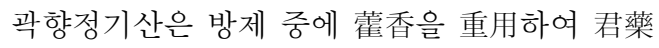
으로 하였다. 그 辛溫한 性味를 취하여 表에 있는 風寒을 푸는 작용이 있고, 또한 그 芳香性으로 인 하여 裏에 있는 濕濁을 化하는 작용이 있으며, 그 리고 辟穢和中과 昇淸降濁의 작용이 있다. 따라 서 霍亂吐㴼를 치료하는 要藥이 된다. 紫蘇葉은 그 性味가 辛溫하여 發汗解表와 行氣寬中의 작용 이 있고, 白芷는 그 性味가 辛溫하여 解表散風· 通䆻止痛과 燥濕止帶의 작용이 있다. 紫蘇葉과 白芷는 모두 辛香發散의 작용이 있는 약물로 蕉 香이 밖으로 風寒의 病邪를 푸는 작용을 증강시 키고, 동시에 안으로는 濕濁을 제거하는 작용을 한다. 따라서 紫蘇葉과 白芷는 臣藥이 된다. 牛夏 栭은 그 性味가 辛溫하여 燥濕化痰·降逆止煰와 消㾂散結의 작용이 있어서 惡心嘔吐를 제거하고, 厚朴은 그 性味가 苦辛溫하여 燥濕除滿과 下氣消 積의 작용이 있고, 陳皮는 그 性味가 辛苦溫하여 理氣健脾와 燥濕化痰의 작용이 있으며, 大腹皮는 그 性味가 辛微溫하여 行氣導滯와 利水消腫의 작
용이 있다. 牛夏·厚朴·陳皮와 大腹皮의 네가지 약물을 같이 配伍하여 사용하면 燥濕行氣와 降逆 和胃의 작용이 있게 되고, 蕉香과 함께 霍亂吐瀉 를 치료한다. 濕阻氣滯와 脘腹㾂悶脹滿 等의 치 료에 가장 적합하다. 또한, 桔梗은 그 性味가 苦辛 本하여 宣肺와 利胸膈間之滯氣의 작용이 있어 㾂 悶을 치료한다. 게다가 肺는 水之上源이고 肺氣 의 宣發과 肅降 기능이 정상적으로 작용하면 通 調水道의 기능이 원활하게 된다. 桔梗이 大腹皮 와 配伍하면 行氣利水의 작용이 있어 濕邪가 小 便으로부터 나가게 된다. 白术은 그 性味가 苦甘 溫하여 補氣健脾와 燥濕利水의 작용이 있고, 获 苓은 그 性味가 甘淡本하여 利水滲濕과 健脾補中 의 작용이 있다. 白术과 获苓을 配伍하면 健脾社 濕의 작용이 있어 脾胃의 運化기능을 돕게 된다. 이상의 牛夏·厚朴·陳皮·大腹皮・桔梗・白术과 获 苓의 여덟가지 약물은 佐藥이 된다. 甘草는 그 性 味가 甘平하여 益氣補中·緩急止痛과 調和藥性의 작용이 있고, 用法 중에 조금 넣은 生瞢은 그 性 味가 辛溫하여 發汗解表와 溫中止嘔의 작용이 있 고, 大東는 그 性味가 甘溫하여 補中益氣와 緩和 藥性의 작용이 있다. 이들 甘草·生薑과 大霖의 세가지 약물을 配伍하면 모든 약물을 조화시키고 營衛를 조화시키며 脾胃를 調理하는 작용이 있어 모두 使藥이 된다. 이상의 모든 약물을 함께 配伍 하여 사용하면 風寒은 밖에서 풀리고 惡寒과 發 熱은 나가며 氣機는 通暢하고 胸膈은 펴지며, 脾 胃는 調和되어 吐瀉가 멈추고 邪氣는 물러나서 正氣는 편안해지고, 正氣는 회복되어 邪氣를 방 어할 수 있어 함께 解表化濕과 理氣和中의 작용 을 거두게 된다.

곽향정기산의 配伍 특징은 세 가지이다. 하나 는 辛溫解表藥으로 發散風寒의 작용이 있고, 苦 溫化濕藥으로 燥濕理氣和中의 작용이 있어 表裏 雙解의 작용을 거두게 된다. 다른 하나는 방제 중 에 蕉香·紫蘇葉·白芷와 桔梗은 外散風寒과 昇發 清陽의 작용이 있고, 厚朴・大腹皮·牛夏栭과 获苓 등은 化濕行氣와 降逆除滿의 작용이 있어 昇清降 濁法을 구현하였다. 마지막으로 본 방제는 疏散 表寒과 芳化濕濁하여 祛邪시키는 작용이 있고, 


\begin{tabular}{|c|c|c|c|c|c|}
\hline A & 蒦 香 3雨 & 君 & 蒦 香 & 辛溫，芳香化濕·墢表解暑・和中止嘔 & 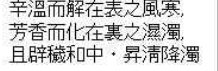 \\
\hline & 紫蘇葉 1兩 & & 厂紫蘇葉 & 辛溫, 發汗解表·行氧寛中 & 辛香墢散, 助蒦香外散風、 \\
\hline & 白 芷 1雨 & 臣 & [皇 芷 & 辛溫, 解表散風・通舁止痛・燥濕止帶 & 寒，兼芳化濕濁 \\
\hline & 半夏䇅 2 兩 & & 一半夏恽 & 辛溫, 燥濕化痰・隆逆止嘔・消㿋散結 & \\
\hline & 厚 朴 2雨 & & 厚 朴 & 苦辛溫, 燥濕除滿·下氣消積 & 燥濕行氣 \\
\hline & 陳 皮 2 兩 & & 陳 皮 & 辛苦溫, 理氣健脾・燥濕化㾳 & 與蒦香治霍亂吐瀉 \\
\hline & 大腹皮 1 兩 & 佐一 & 大腹皮 & 辛微溫, 行氣導滯·利水消腫 & \\
\hline & 桔 梗 2兩 & & 桔 梗 & 苦辛平, 宣肺化痰 - 利胸膈間之滯氣 & 助濕邪便排出 \\
\hline & 白 术 2 兩 & & 白求 & 苦甘溫, 補氣,健脾 - 燥濕利水 & 健脾社湟 \\
\hline & 获 苓 1 兩 & & 获 苓 & 甘淡平, 利水渚濕 - 健脾補中 & 助脾胃之運化 \\
\hline & 甘草 2 兩 & & 「甘草 & 甘平，㿽氣補中+調和藥性 & \\
\hline & 生 薑 3片 & 使 & 生 薑 & 辛溫, 發汗解表·溫中止嘔 & 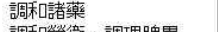 \\
\hline & 大 霜 1枚 & & 大霜 & 甘溫, 補中六氣・緩和藥性 & 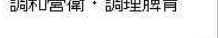 \\
\hline
\end{tabular}

B

\begin{tabular}{|c|c|c|c|c|}
\hline 蒦 香 3 兩 & 君 & 蒦 香 & 辛溫, 芳香化濕·墢表解暑·和中止嘔 & 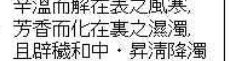 \\
\hline 半夏㖣 2 兩 & & 「半夏檜 & 辛溫，燥濕化痰·降逆止嘔·消㾙散結 & \\
\hline 厚 朴 2 兩 & 臣 & [厚 朴 & 苦辛溫, 燥濕除滿. 下氧消積 & 仃来洞独 \\
\hline 紫蘇葉 1 兩 & & 紫蘇葉 & 辛溫，發汗解表・行氧寛中 & \\
\hline 白芷 1 兩 & & 白芷 & 辛溫，解表散風・通敫止痛・燥濕止帶 & 解表散 \\
\hline 陳 皮 2兩 & & 陳 皮 & 辛苦溫, 理氧健脾·燥濕化痰 & \\
\hline 大腹皮 1 兩 & 佐一 & 大腹皮 & 辛微溫, 行氧導滯·利水消腫 & 里采化沾 \\
\hline 白 术 2 兩 & & 白 术 & 苦甘溫，補氧健脾 - 燥濕利水 & \\
\hline 获 苓 1 雨 & & 获 苓 & 甘淡平, 利水洷濕 - 健脾補中 & 腮㭕濕，助腮莦之運化 \\
\hline 桔 梗 2兩 & & 一桔 梗 & 苦辛平，宣肺化痰 - 利胸膈間之滯氣 & 宣肺利肺 \\
\hline 甘草 2兩 & & [甘 草 & 甘平，益氣、補中·調和藥性 & \\
\hline 生 薑 3片 & 使 & 生 蓄 & 辛溫, 墢汗解表・溫中止嘔 & 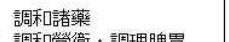 \\
\hline 大霜 1 枚 & & 大轓 & 甘溫, 補中益氧 - 緩和藥性 & 調札 \\
\hline
\end{tabular}

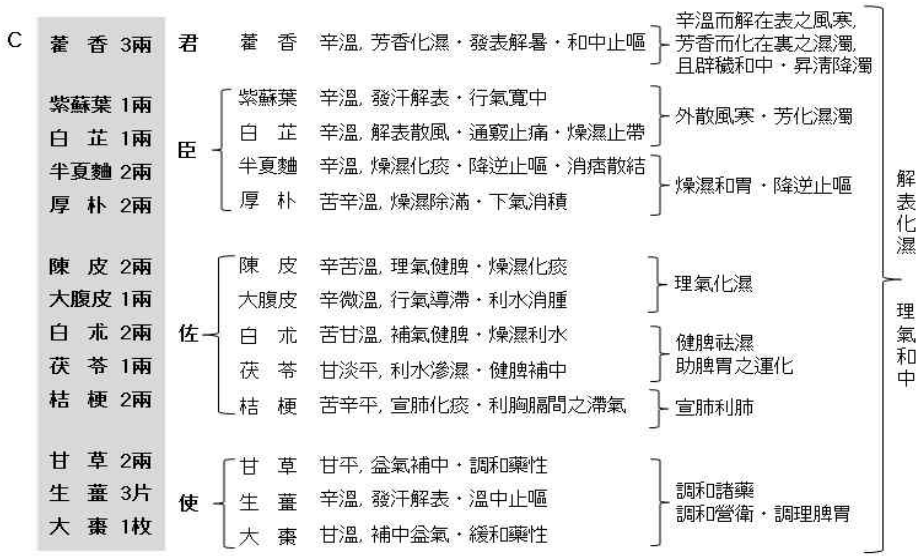

Fig. 12. Analyzing combination of Agastache Powder to Rectify the Ki 


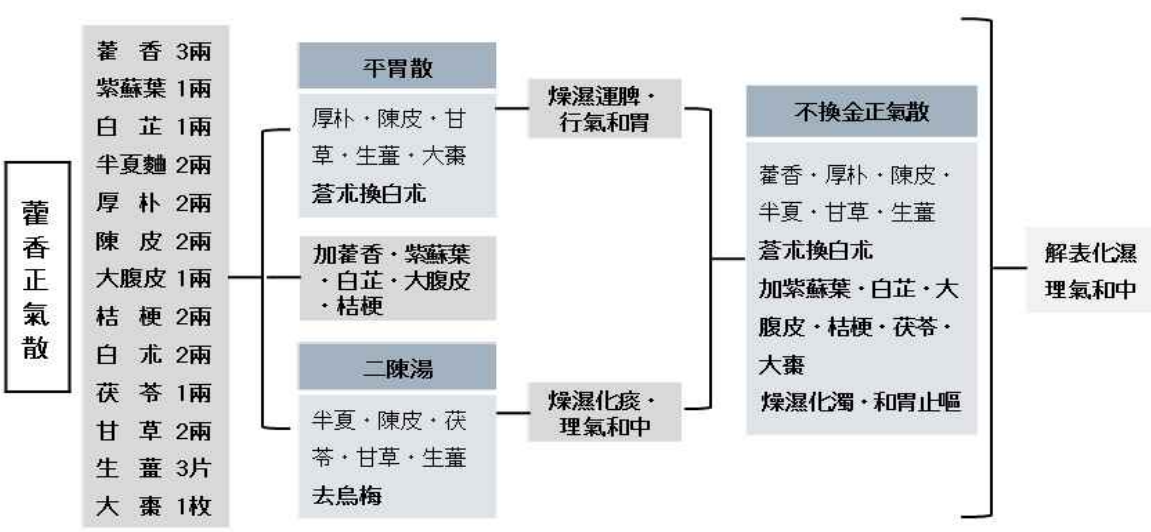

Fig. 13. Analysis of Agastache Powder to Rectify the Ki using basic formula

또한, 健脾補中하여 扶正시키는 작용이 있다. 따 라서 邪氣를 제거해도 正氣를 다치지 않게 되고 正氣를 도와서 邪氣를 제거하는데 도움을 주어 양자는 상부상조하여 扶正社邪의 작용을 거두게 한다. 이상의 藥物配伍에 근거하여 配伍分析을 도식화하면 그림 $12-\mathrm{A}$ 와 같다.

또한, 곽향정기산은 平胃散（蒼术・厚朴・陳皮 · 甘草 - 生薑 - 大霖) 과 二陳湯 (牛夏 $\cdot$ 陳皮 $\cdot$ 白获 苓・甘草・生薑 - 烏梅)의 용량을 반으로 줄이고 蒼术을 白术로 바꾸며 烏梅는 빼고, 다시 蕉香 . 紫蘇葉・白芷・大腹皮와 桔梗을 넣어 蕉香을 君 藥으로 한 方劑로 不換金正氣散（蕉香 - 厚朴 - 蒼 术・陳皮 - 牛夏 - 甘草 - 生薑)에서 蒼术을 白术至
바꾸고, 다시 紫蘇葉・白芷 - 大腹皮 $\cdot$ 桔梗 $\cdot$ 茯苓 과 大霖를 넣은 不換金正氣散의 加減方으로 볼 수 있다 (Fig. 13).

그리고 곽향정기산의 조성약물의 燕物配伍를 분석할 때 중요한 조성약물의 氣味藥性分析을 제 시하였다 ${ }^{30)}$ (Table 5).

결론적으로 한의과대학의 공통교재 편찬에서 방제학각론의 개별방제에 대한 방제분석은 다음의 원칙을 정하여 진행하는 것이 방제학교육의 목표 를 효과적으로 달성할 수 있을 것으로 생각된다.

원칙의 첫째는 원 출전의 万劑를 기준으로 한다. 단, 현행 같은 이름의 방제의 변화가 심하여 통상 사용하는 방제는 예외로 한다. 둘째는 조성약물

Table 5. Analyzing Ingredients of Agastache Powder to Rectify the Ki Using Properties and Tastes of Materia Medica

\begin{tabular}{|c|c|c|c|}
\hline 藥物 & 性味 & 歸經 & 작용 \\
\hline 嚄香 & 辛溫 & $\begin{array}{l}\text { 脾經 胃經·肺經 } \\
\end{array}$ & 芳香化濕 發表解暑·和中止嘔 \\
\hline 紫蘇葉 & 辛溫 & 肺經 脾經 & 發汗解表 行氣寬中·解魚蟹毒 \\
\hline 白芷 & 辛溫 & 肺經 胃經 & 解表散風 通憿止痛·燥濕止帶.消腫排膿 \\
\hline 牛夏 & 辛溫有毒 & 肺經 脾經·胃經 & 燥濕化痰 降逆止嘔·消㾂散結, 外用消腫止痛 \\
\hline 厚朴 & 苦辛溫 & 脾經 胃經·肺經·大腸經 & 燥濕除滿 下氣消積·消痰本喘 \\
\hline 陳皮 & 辛苦溫 & 脾經 肺經 & 理氣健脾 燥濕化痰 \\
\hline 大腹皮 & 辛微溫 & 脾經 胃經·大腸經 小腸經 & 行氣淺滯 利水消腫 \\
\hline 桔梗 & 苦辛本 & 肺經 & 宣肺化痰 利咽 排膿 \\
\hline 白术 & 苦甘溫 & 脾經 胃經 & 補氣健脾 燥濕利水·止汗安胎 \\
\hline 茯苓 & 甘淡本 & 心經 脾經·腎經 & 利水渗濕 健脾補中.寧心安神 \\
\hline 甘草 & 甘本 & 心經 肺經·脾經·胃經 & 益氣補中 潤肺止咳·清熱解毒·緩急止痛 調和藥性 \\
\hline 生薑 & 辛溫 & 肺經 脾經·胃經 & 發汗解表 溫中止嘔·溫肺止咳 \\
\hline 大染 & 甘溫 & 脾經 胃經 & 補中谷氣 養血安神·緩和藥性 \\
\hline
\end{tabular}


의 配伍는 七情配伍 등 藥對로 분석한다. 셋째는 조성약물의 작용과 적응증 등은 氣味藥性論으로 분석하고 도표화 한다. 넷째는 방제를 君臣佐使 論으로 분석하고 도식화 한다. 다섯째는 기본방 의 合方加減으로 분석하고 도식화 한다.

\section{$\mathrm{V}$. 결 론}

한의과대학의 방제학 공통교재 중 방제학각론 에 수재할 개별방제의 방제분석을 蕉香正氣散을 실례를 들어 방제분석의 다음과 같은 표준안을 제시하고자 한다.

1. 원 출전의 方劑를 기준으로 방제분석을 해야 한다. 조성약물의 配伍는 七情配伍 등 藥對로 분 석해야한다. 조성약물의 작용과 적응증 등은 氣 味藥性論으로 분석하고 도표화 해야한다. 방제를 君臣佐使論으로 분석하고 도식화 해야한다. 기본 방의 合方加減으로 분석하고 도식화 해야한다.

2. 蕉香正氣散은 『太本惠民和劑局方』에서 처 음으로 수재되었고, 外感風寒과 內傷濕濁으로 생 긴 霍乳吐瀉를 치료하는 常用方이며, 그 조성약 물은 大腹皮・获苓・白芷・紫蘇葉・陳皮・桔梗

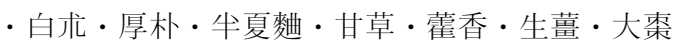
의 13 종이다.

3. 蕉香正氣散을 君臣佐使論으로 분석하면 君 藥은 蕉香이고, 臣藥은 紫蘇葉과 白芷이며, 佐藥

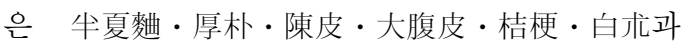
获苓이고, 使藥은 甘草 - 生瞢과 大荣이다.

4. 蕉香正氣散은 平胃散과 二陳湯의 용량을 반 으로 줄이고 蒼术을 白术로 바꾸며 烏梅는 빼고, 다시 蕉香・紫蘇葉 - 白芷 · 大腹皮와 桔梗을 넣어 蕉香을 君藥으로 한 方劑로 不換金正氣散에서 蒼 术을 白术로 바꾸고, 다시 紫蘇葉 - 白芷 - 大腹皮 - 桔梗 - 获苓과 大菓를 넣은 不換金正氣散의 加 減方으로 볼 수도 있다.

결론적으로 개별방제에 대한 방제분석의 원칙 을 정하여 표준화된 방제분석을 제시하여 방제학 교육이 이루어진다면 한의과대학의 방제학교육을 효과적으로 달성할 수 있을 것으로 판단된다.

\section{참 고 문 헌}

1. Kim DH, Shin SS. Analysis of Introduction to Science of Prescriptions in Teaching Materials Related with Science of Prescriptions at Colleges of Korean Oriental Medicine and Colleges of Traditional Chinese Medicine. The Korean Journal of Oriental Medical Prescription. 2003;11:1-18.

2. Chen C, Pei ZY, Chen SW. Prescriptions from the Great Peace Imperial Grace Pharmacy. 1st ed. Haikou city: Hainan Press. 2002:81.

3. Kim DH, Seo BI, Kim BK, Kim GC, Shin SS. Standard Principles for the Designing of Prescriptions - The Theory for Monarch, Minister, Adjuvant and Dispatcher. The Korean Journal of Oriental Medical Prescription. 2003; $11: 1-18$.

4. Yun GY. Methodology of Korean Medicine. Seoul:Seongbo publishing. 1983:238-9.

5. Shin SS. Analysis of the Properties and Tastes In Hyeongok's Formulas for Invigorating Five Viscera and their Ingredients. The Korean Journal of Oriental Medical Prescription. 2011; 19:133-5.

6. Wu K. Wu Kun's Medical Encyclopedia. 1st ed. Beijing:China Press of Traditional Chinese Medicine. 1999:54.

7. Wang Y. ${ }^{\circledR}$ Medical Formulas Collected and Analyzed』. 1st ed. Beijing:China Press of Traditional Chinese Medicine. 1999:168.

8. Li F. Formula Science (Volume 2). 2nd ed. Beijing:People's Medical Publishing House. 2011:1483-6.

9. Yun GY. Clinical Formula Science of Korean Medicine. Seoul:Myeongbo Press. 1985:75.

10. Yun GY. The Theory for Four-Constitution Medicine. 3rd ed. Seoul:Sungil Press. 1980: 357.

11. Yun YG. Diagram for Korean Formula and it's Interpretation. 3rd ed. Seoul:Euiseongdang. 2007:452. 
12. He L. Compendium of Practical Formula. 1st ed. Xian:Shanxi scientific \& Technical Publishers. 1991:425.

13. Xu JQ, Wang MZ. Formula Science. 1st ed. Beijing:People's Medical Publishing House. 1997:179.

14. Duan FJ. Formula Science. 1st ed. Beijing:China Press of Traditional Chinese Medicine. 1999: 527.

15. Liu XW, Tang QX. Interpretation in Detail and Interesting Memory for Formula. 1st ed. Shenyang: Liaoning scientific \& Technical Publishers, 1999:227.

16. Xu JQ. Formula Science. 1st ed. Shanghai: Shanghai scientific \& Technical Publishers. 2000:179.

17. Dun BS. Shorthand Encyclopedia for Practical Formula. 1st ed. Xian:World Publishing Company, 2001:229.

18. Xie M. Formula Science. 1st ed. Beijing: People's Medical Publishing House. 2002:368-9.

19. Liu GW. Formula Science. 1st ed. Beijing: Huaxia Publishing House. 2002:97-8.

20. Li QY, Yang B. Chart Solution for Formula Science. 1st ed. Beijing:People's Medical Publishing House. 2004:182.

21. Zhang MQ. Modern Clinical Formula Science. 1st ed. Beijing:People's Medical Publishing House. 2004:629-30.

22. Zhao ZZ. Diagram for One Hundred Formula. 1st ed. Beijing:People's Medical Publishing House. 2005:180.

23. Yan YQ. Introduction to Formula Science of New Concept. 1st ed. Shanghai:Shanghai scientific \& Technical Publishers. 2005:459.

24. Qiu DW, Feng Y, Zou KY. Morden Formula Science. 1st ed. Beijing:Chinese Ancient Books Publishing House. 2006:426-7.

25. Ni C. New Editing Formula Science. 1st ed. Beijing:People's Medical Publishing House. 2006:452-3.

26. Han XH. Notes of Formula Science. 1st ed.
Beijing:Science Press. 2006:124-5.

27. Han XH. Sticking out a mile for Formula. 1st ed. Guangzhou:Guangdong scientific \& Technical Publishers. 2008:162-3.

28. Chen CZ. Treatment Method and Formula in Traditional Chinese Medicine. 5th ed. Beijing: People's Medical Publishing House. 2009:337.

29. Fan Y, Ma J. Shorthand speed Pocket book for Formula. 1st ed. Shenyang:Liaoning scientific \& Technical Publishers. 2010:229.

30. Gao XM, Zhong GS. Application of Differential for Commonly Used Clinical Formula and Materia Matica 1st ed. Beijing:People's Medical Publishing House. 2003: 6-8, 17, 241-2, 250, 263, 342-3, 376, 553, 570, 698, $706-9$. 